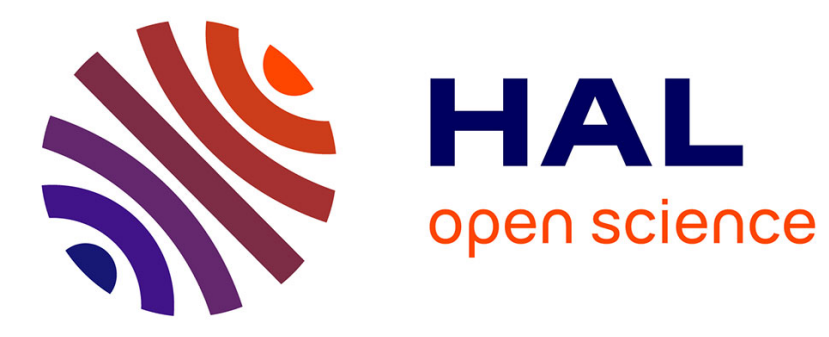

\title{
Organogels from trehalose difatty esters amphiphiles
}

Geoffrey Hibert, Martin Fauquignon, Jean-François Le Meins, Didier Pintori,

Etienne Grau, Sébastien Lecommandoux, Henri Cramail

\section{To cite this version:}

Geoffrey Hibert, Martin Fauquignon, Jean-François Le Meins, Didier Pintori, Etienne Grau, et al.. Organogels from trehalose difatty esters amphiphiles. Soft Matter, 2019, 15 (1), pp.956-962. 10.1039/C8SM02244E . hal-01981715

\section{HAL Id: hal-01981715 \\ https://hal.science/hal-01981715}

Submitted on 20 Nov 2019

HAL is a multi-disciplinary open access archive for the deposit and dissemination of scientific research documents, whether they are published or not. The documents may come from teaching and research institutions in France or abroad, or from public or private research centers.
L'archive ouverte pluridisciplinaire HAL, est destinée au dépôt et à la diffusion de documents scientifiques de niveau recherche, publiés ou non, émanant des établissements d'enseignement et de recherche français ou étrangers, des laboratoires publics ou privés. 


\title{
Organogels from trehalose difatty esters amphiphiles ${ }^{\dagger}$
}

\author{
G. Hibert, ${ }^{a, b}$ M. Fauquignon, ${ }^{a, b}$ J.-F. Le Meins, ${ }^{a, b}$ D. Pintori, ${ }^{c}$ E. Grau, ${ }^{* a, b}$ S. \\ Lecommandoux, ${ }^{* a, b}$ and H. Cramail ${ }^{* a, b}$
}

\begin{abstract}
Saccharide diesters have been recently shown to be excellent gelator of vegetable oils. In this paper, different fatty acid trehalose diesters were synthesized by a selective enzymatic transesterification performed only on the primary hydroxyl group of the trehalose. The resulting trehalose diesters demonstrated their ability to self-assemble in a large variety of edible vegetable oils with a minimum gelation concentration of $0.25 \mathrm{wt} \% / \mathrm{v}$. Microscopic analysis and $\mathrm{X}$-ray scattering studies indicate that the gels are obtained by the self-assembly of trehalose diesters in cristalline fibers constituting the tridimensional network. The rheological study revealed that the properties of the gels depend on the kind of fatty acid grafted on the trehalose but are also influenced by the vegetable oil composition.
\end{abstract}

\section{Introduction}

The development of oil-structuring agents has received a huge interest in the last decades due to their interest in food, ${ }^{1-3}$ cosmetics $^{4}$ and pharmaceutics.5,6 Among the strategies to structure vegetable oils, the formation of gels is an approach mostly developed, as attested by the large number of gelators described in literature. ${ }^{7,8}$ The latter can be divided in two groups according to their molecular weight: the polymeric ones $^{9}$ (whose $\mathrm{M}_{\mathrm{n}}$ is $>3000 \mathrm{~g} \cdot \mathrm{mol}^{-1}$ ) and the low molecular weight gelators (LMWG) with a $M_{n}$ value lower than 3000 g.mol-1.10,11 LMWG, that were focused in this study, are generally amphiphilic molecules, which self-assemble in highly ordered structures creating tridimensional networks in oil. ${ }^{11-13}$ Their self-assembly is driven by weak interactions such as hydrogen bonding, electrostatic forces, $\pi-\pi$ stacking or Van der Waals interactions. Some of these LMWG self-assemble into fibrillar networks, often referred as SAFiN that stands for "SelfAssembled Fibrillar Networks". ${ }^{14,15}$ In this case, the 3D network is formed by the entanglement of crystalline fibers of selfassembled gelators. ${ }^{7,10}$

Nowadays, due to environmental and economic concerns, the development of functional molecules from biomass to replace petroleum-based ones are presenting a growing interest with significant promise. ${ }^{16}$ Thanks to the biorefineries, ${ }^{17,18}$ the access to a wide platform of precursors is available to design amphiphilic bio-sourced molecules which can be used as gelators. ${ }^{19-22}$ Several researches have presented novel biobased LMWG from saccharide ester derivatives. Indeed, these LMWG have the advantage to be renewable but also nontoxic. The saccharide esters are already largely employed in industry for their surfactant properties.

Dordick and co-workers were the first to study the gelation properties of such saccharide esters. ${ }^{23,24}$ The authors prepared trehalose diesters by enzymatic esterification of the primary hydroxyl groups in 6,6'-position with short vinyl esters (C1 to C14). They demonstrated that the trehalose diesters can gel various organic solvents as well as olive oil. Moreover in the specific case of short alkyl chains (in particular (4) the authors demonstrated that the gels obtained in organic solvents such as ethyl acetate or acetonitrile, are formed by self-assembly into fibrillary network. John and co-workers have also reported the gelation properties of various saccharide diesters. ${ }^{25,26}$ Similarly, diesters of mannitol and sorbitol were prepared via enzymatic esterification of primary alcohols. These molecules have shown excellent gelation properties in organic solvents as well as in edible vegetable oils and could thus be used in food or cosmetic applications.

However, to the best of our knowledge, there is no full comprehensive investigation of $100 \%$ bio-sourced trehalose fatty esters as organogelators. Some studies have reported the enzymatic esterification of trehalose with fatty acid derivatives 27-29 Generally, lipase B from Candida antarctica is employed that allows a one step and selective esterification on primary alcohols in mild conditions with low toxic reagents and solvents. In a previous study, we already prepared trehalose diesters by selective enzymatic esterification of vinyl undecenoate on the 6-6' hydroxyl group of the trehalose in order to design saccharide-containing polymers by ADMET. ${ }^{30}$ In this work, we aimed at investigating the ability of trehalose diesters, exhibiting various fatty acid chains (from C11 to C22), to gel vegetable oils. To this purpose, we have synthesized, by the enzymatic route previously reported, 30 six trehalose diesters and investigated their gelation properties in three selected vegetable oils. Indeed, the structure (size, number of unsaturations, stereochemistry of the unsaturation) of the lipidic chain of the trehalose diester together with the nature of the vegetable oil have an effect on the gelator self-assembly and thus on the gel properties. The properties of the gels were analysed by microscopy, X-ray scattering and rheology.

\section{Experimental}

\section{Materials}

Potassium hydroxide ( $\mathrm{KOH}$, pellets), 2-methyltetrahydrofuran (99\%), vinyl acetate (99\%), Lipase B from Candida antarctica (CALB) were purchased from Sigma-Aldrich. 10-undecenoic acid were supplied from Alfa Aesar. Palladium acetate (98\%), were purchased from $\mathrm{TCl}$. Oleic acid (99\%), stearic acid (99\%), elaidic acid (99\%), erucic acid (99\%) and linoleic acid (99\%) 
were purchased from Nu-Check Prep. Anhydrous trehalose (99\%) was bought from Fisher. Vegetable oils and pharmaceutical grade oils were kindly provided by ITERG.

\section{Gelator synthesis}

Vinyl ester (1) (transvinylation of fatty acid): Fatty acid (1 eq.) and a 15 eq. excess of vinyl acetate (VAC) was poured in a CEM Discover SP microwave reactor vial. Then, the palladium acetate (0.05 eq.), and the potassium hydroxide ( 0.10 eq.) were added and the resulting reaction mixture was stirred under microwave at $60{ }^{\circ} \mathrm{C}$ for $2 \mathrm{~h}$. The reaction mixture was diluted in dichloromethane (DCM) and then filtrated over celite to remove the palladium acetate, before removing the solvent and the unreacted vinyl acetate with a rotary evaporator. The resulting residue was purified by silica gel flash chromatography using an elution gradient of $2-5 \% \mathrm{MeOH}$ in DCM to give the vinyl ester. Purity was confirmed by NMR spectroscopy. Yield: $95 \%$.

Trehalose diester (2) (enzymatic esterification of trehalose): The lipase $(2.8 \mathrm{~g})$ was added to a mixture of trehalose $(3 \mathrm{~g}, 9$ $\mathrm{mmol})$, vinyl ester $(2.5 \mathrm{eq})$ in dry $\mathrm{mTHF}(40 \mathrm{~mL})$. The reaction mixture was stirred at $45{ }^{\circ} \mathrm{C}$ for $72 \mathrm{hr}$. After the reaction time, mTHF was added to dissolve the diesters of trehalose, then the reaction mixture was filtered and the solvent was removed in rotary evaporator. The obtained crude product was purified by silica gel flash chromatography using an elution gradient of 525\% methanol in EtOAc-DCM (1:1) to give pure trehalose diesters as white solids. Purity was confirmed by NMR spectroscopy (see ESI). Yield: $50 \%$.

\section{Vegetable oil-based gel preparation and gelation test}

Gel samples were prepared by adding a precise amount of trehalose diesters to a desired solvent (vegetable oils and pharmaceutical grade oils), heating $\left(T \approx 120-150^{\circ} \mathrm{C}\right)$ and stirring until complete dissolution of the diesters in the vegetable oils. After getting a homogeneous solution, the mixture was cooled down to room temperature. The sample vials were inverted to qualitatively evaluate the gel formation.

To assess the efficiency of these trehalose diesters as gelators, the minimal gelation concentration (MGC) of each diester was determined. The MGC was estimated by diluting the gel until the formation of a solution (qualitative vial inversion method).

\section{Characterization of Vegetable Oil-based Gels}

Optical microscopy and scanning electron microscopy (SEM)

Optical microscopy images were recorded on an Axioskop 40 Zeiss microscope equipped with a digital camera (Canon Powershot A640) connected to the computer.

SEM images were recorded on a MEB HITACHI TM-1000 having acceleration voltage of $15 \mathrm{kV}$. Samples were previously coated with gold film (15- $20 \mathrm{~nm})$.

Due to the presence of the vegetable oil, the observation of the organogels by optical microscopy or scanning electron microscopy was difficult. Consequently, the gels were prepared in ethyl acetate (EtOAc) at $2 \mathrm{wt} \% / \mathrm{v}$ then EtOAc was evaporated to obtain the xerogels. These xerogels were observed by phase contrast microscopy, dark field microscopy and scanning electron microscopy.

\section{X-ray scattering (XRS)}

The XRS experiments were conducted at the Centre de Recherche Paul Pascal (CNRS - University of Bordeaux) with a microfocus rotating anode $\mathrm{X}$-ray source (Rigaku MicroMax-007 HF) combined with performant multi-layers optics and a 3pinholes collimation that provide an intense $X$-ray beam on the sample. The sample, mounted on $X-Y$ stage, was held in a Lindemann capillary and placed in an oven providing a temperature control of $0.1 \mathrm{~K}$. A 2-dimensional detector (Image plate from Mar Research) was collecting the scattered radiations. Calibration of the sample-detector distance was performed using silver behenate as a reference.

\section{Oscillatory rheology}

Storage modulus $G^{\prime}$ and loss modulus $G^{\prime \prime}$ of the gels were determined on an Anton Paar MCR 301 stress controlled rheometer. Temperature was controlled on the bottom plate by Peltier effect. The geometry used for the measurements was a cone-and-plate $\left(50 \mathrm{~mm} / 2^{\circ}\right)$. The gels were loaded between the cone-and-plate and melted at $130{ }^{\circ} \mathrm{C}$ for $3 \mathrm{~min}$ and then cooled down to room temperature. The measurements were started after $10 \mathrm{~min}$ of sample rest.

\section{Instrumentation}

Flash chromatography was performed on a Grace Reveleris apparatus, employing cartridges from Grace equipped with ELSD and UV detectors at 254 and $280 \mathrm{~nm}$. Elution solvents are dependent on the sample and are mentioned in the experimental parts. Differential Scanning Calorimetry (DSC) measurements were performed on DSC Q100 (TA Instruments). The sample was heated from $-150^{\circ} \mathrm{C}$ to $170^{\circ} \mathrm{C}$ at a rate of $10^{\circ} \mathrm{C} \cdot \mathrm{min}^{-1}$. Consecutive cooling and second heating runs were also performed at $10^{\circ} \mathrm{C} \cdot \mathrm{min}^{-1}$. All NMR spectra were recorded at $298 \mathrm{~K}$ on a Bruker Avance 400 spectrometer operating at $400 \mathrm{MHz}$.

\section{Results and discussion}

\section{Gelator synthesis}

Trehalose diesters were synthesized according to a two-step procedure previously reported, ${ }^{27}$ i.e. a transvinylation of fatty acids to get vinyl esters followed by an enzymatic transesterification of trehalose with vinyl esters (Scheme 1, see supporting information for more details, Figures S1-S6). 


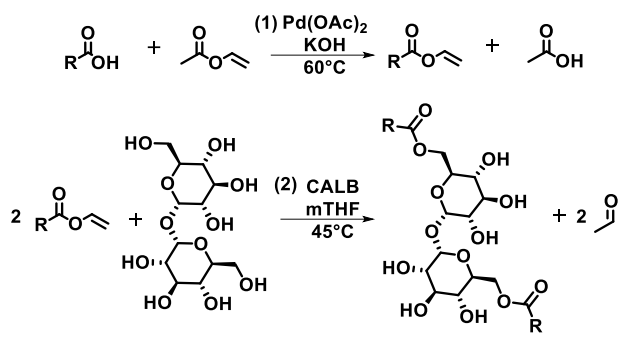

Scheme 1: Two-step procedure for the synthesis of trehalose diesters, (1) transvinylation step, (2) enzymatic esterification

Six different fatty acids have been used to synthesize a platform of six trehalose diesters (Figure 1) in order to evaluate the influence of the lipophilic structure on the gel properties.

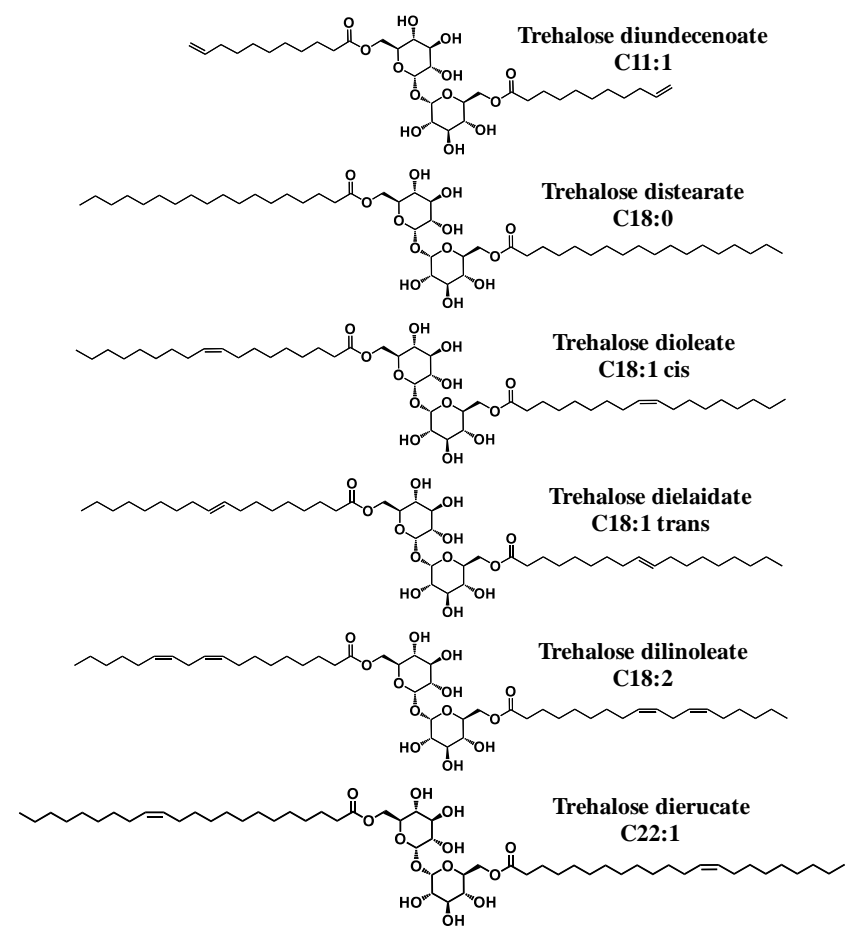

Figure 1: Platform of the synthesized trehalose diesters.

\section{Vegetable oil-based gel preparation and gelation efficiency}

As an example, trehalose dioleate was used to gel various vegetable oils and two pharmaceutical oils (Figure 2). Gels prepared with three vegetable oils (olive, linseed and castor) were studied in details in order to get better insights on the gelation mechanism and gel properties. These three oils have been selected due to their different composition: the olive oil is rich in oleic acid (C18:1 cis), the linseed oil in linoleic acid (C18:2) and the castor oil in ricinoleic acid (C18:1-OH).

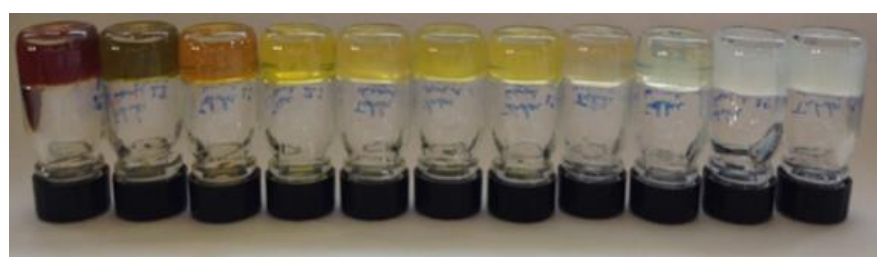

Figure 2: Gels prepared with trehalose dioleate as gelator $(2 \mathrm{wt} \% / \mathrm{v})$ in different vegetable oils. From left to right: pumpkin oil, grapeseed oil, canola oil, linseed oil, walnut oil, olive oil, sunflower oil, castor oil, soybean oil, Labrafac Lipophil WL and Mygliol 812.
To evaluate the efficiency of these trehalose diesters as gelators, the minimal gelation concentration (MGC) of each diester was estimated in the three selected vegetable oils. Data are summarized in Table 1.

Table 1: MGC values of gels in olive, linseed and castor oils with different trehalose diesters as gelators.

Minimal gelation concentration (MGC)

Gelator

$$
\text { [wt\%/v] }
$$

Olive oil Linseed oil

Castor oil

\begin{tabular}{cccc}
\hline Trehalose diundecenoate & 0.5 & 0.5 & 0.25 \\
\hline Trehalose distearate & 0.75 & 1.0 & 0.5 \\
\hline Trehalose dioleate & 0.75 & 0.5 & 0.5 \\
\hline Trehalose dielaidate & 0.5 & 0.5 & 0.25 \\
\hline Trehalose dilinoleate & 0.5 & 0.5 & 0.25 \\
\hline Trehalose dieruçate & 0.5 & 0.5 & 0.5 \\
\hline
\end{tabular}

Gels were obtained in the three selected vegetable oils. All the glycolipids displayed excellent gelation properties in vegetable oil with low MGC values ( $<1 \mathrm{wt} \% / \mathrm{v}$ ). The MGC was found to be independent of the vegetable oil type and independent of the fatty chain grafted on the trehalose. This is in accordance with what was previously observed in the literature. ${ }^{25,26}$

DSC was also performed on the gels to determine the temperature $\mathrm{T}_{\text {gel-sol }}$ corresponding to the gel-to-sol transition temperature. This temperature is attributed to the melting of the crystalline 3D network (solid content of a gel).

In all cases, $\mathrm{T}_{\text {gel-sol }}$ increases with the concentration of trehalose diester and was comprised between 100 and $120^{\circ} \mathrm{C}$ in castor oil and between 120 and $140{ }^{\circ} \mathrm{C}$ in olive and linseed oils and appeared irrespective of the gelator used (see Table S1).

\section{Morphological study}

\section{Optical microscopy and scanning electron microscopy (SEM)}

To analyze the physical gels by optical microscopy or scanning electron microscopy (SEM), the vegetable oil has to be removed without disrupting the gel structure. Moreover, the synthesized trehalose diesters can also gel some organic solvents such as ethyl acetate (EtOAc). Therefore, organogels in EtOAc at 2 wt\%/v were prepared, allowing an easy removal of the organic solvent. The xerogels so-obtained were directly observed by phase contrast microscopy (Figure 3a,c) and dark field microscopy (Figure $\mathbf{3 b}$,d) and were also analysed by SEM (Figure 3e,f). The optical microscopy analysis revealed that trehalose diesters self-assembled in a 3D-network of fibers. Such morphology was independent of the trehalose diester used for the gelation. A clear fibrous network was also observed by SEM (Figure 3). The trehalose diesters form a selfassembled fibrillar network referred as SAFiN. However, it was 
difficult to evaluate the size of these fibers, the latter resulting from the assembly of several smaller fibrils. This kind of selfassembly was already reported in the literature for similar gelators. ${ }^{26}$
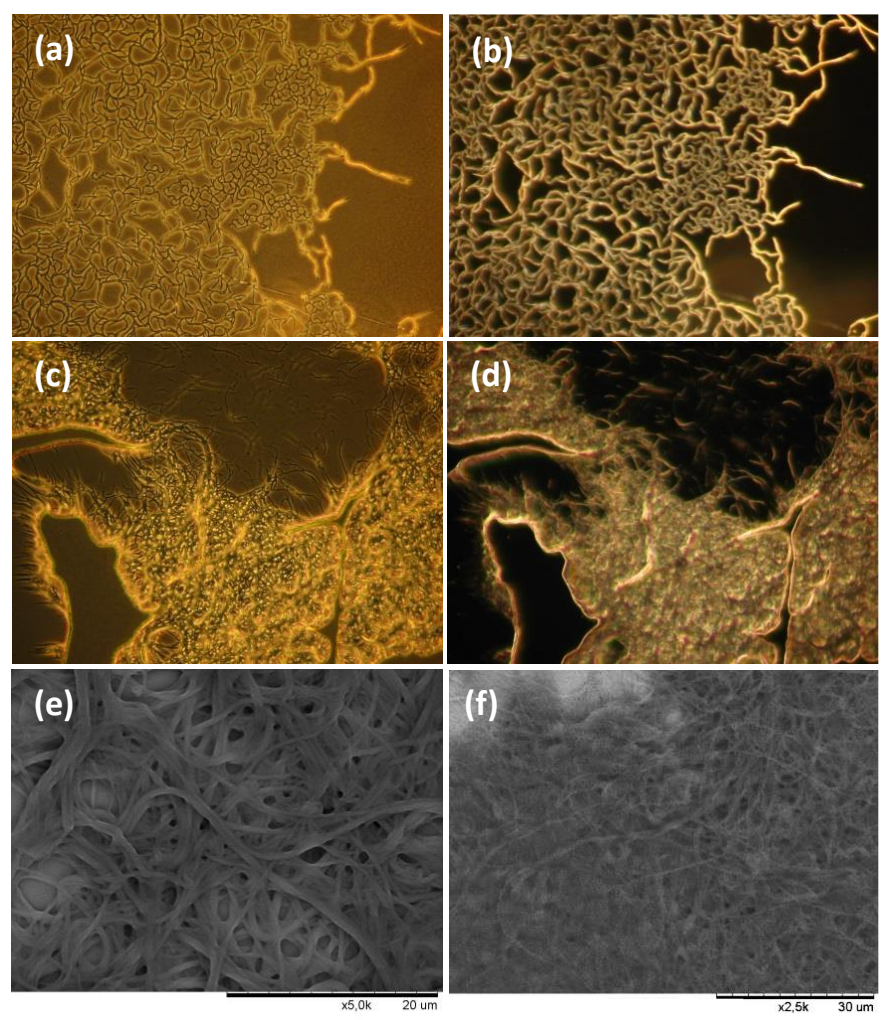

Figure 3: Optical micrograph of xerogel of trehalose dioleate $2 \mathrm{wt} \% / \mathrm{v}$ in EtOAc observed in phase contrast (a) and observed in dark field (b); Optical micrograph of xerogel of trehalose dielaidate $2 \mathrm{wt} \% / \mathrm{v}$ in EtOAc observed in phase contrast (c) and observed in dark field (d); SEM images of trehalose dielaidate $2 \mathrm{wt} \% / \mathrm{v}$ xerogel in EtOAc (e) and SEM images of trehalose dioleate $2 \mathrm{wt} \% / \mathrm{v}$ xerogel in EtOAc (f).

\section{X-ray scattering (XRS)}

X-Ray scattering (XRS) was then performed on gels prepared in castor oil ( $5 \mathrm{wt} \% / \mathrm{v})$ and on the corresponding neat trehalose diester. The XRS patterns of the gels show well-ordered multilayer stacking patterns with periodicity between 2.2 and $4.3 \mathrm{~nm}$ that is long d-spacing values (see Figure S7). These values differ according to the trehalose diester employed and testified of the packing of acyl chain 3D conformation. The more is the acyl chain bent, the smaller is the d-spacing. Besides, XRS patterns of the gels show primary peaks relatively close to the ones observed for the pure trehalose diesters (Table 2). Thus, the self-assembly of trehalose diesters in vegetable oils was relatively close to the one of the pure trehalose diesters. Similar results concerning the self-assembly of trehalose diesters in organic solvents or other saccharide diesters in vegetable oils have been reported by Dordick and co-workers. ${ }^{24}$ SAFiN was formed by a three step process (see Figure 4). The saccharide diesters are stacked into multilayers to form fibers (Figure 4a). The combination of these fibers leads to fibrous (bigger fibers - Figure $\mathbf{4 b}$ ). By entanglement of these fibrous, a 3D network is thus obtained (Figure 4c). The main driving force for this self-assembly is most probably the incompatibility of the saccharide moieties in the oil phase, together with weak interactions such as hydrogen bonds between each trehalose moieties and Van der Waals interactions between the fatty acid chains. The d-spacing is thus directly linked to the acyl chain length. Finally, one could mention that trehalose distearate, dierucate and dielaidate exhibit two d-spacings in bulk and in gel. This could be due to the polymorph crystallization due to different packing of the fatty acid chain which have been already reported for stearic acid, ${ }^{31}$ erucic acid ${ }^{32}$ and elaidic acid..$^{33}$

Table 2: Characteristic distances obtained from XRS analysis on neat trehalose diesters and on gels prepared in castor oil at $5 \mathrm{wt} \% / \mathrm{v}$.

\begin{tabular}{ccc}
\hline Gelator & $\begin{array}{c}\text { d-spacing } \\
\text { pure trehalose } \\
\text { diesters [nm] }\end{array}$ & $\begin{array}{c}\text { d-spacing } \\
\text { gel in castor oil } \\
(\mathbf{5} \text { wt\%/v) [nm] }\end{array}$ \\
\hline Trehalose dioleate & 3.2 & 3.3 \\
\hline Trehalose distearate & $3.8 / 3.2$ & $4.8 / 3.3$ \\
\hline Trehalose diundecenoate & 2.2 & 2.3 \\
\hline Trehalose dierucate & $4.3 / 3.7$ & $4.5 / 3.7$ \\
\hline Trehalose dilinoleate & 3.2 & 3.2 \\
\hline Trehalose dielaidate & $4.2 / 3.18$ & $4.1 / 3.3$ \\
\hline
\end{tabular}

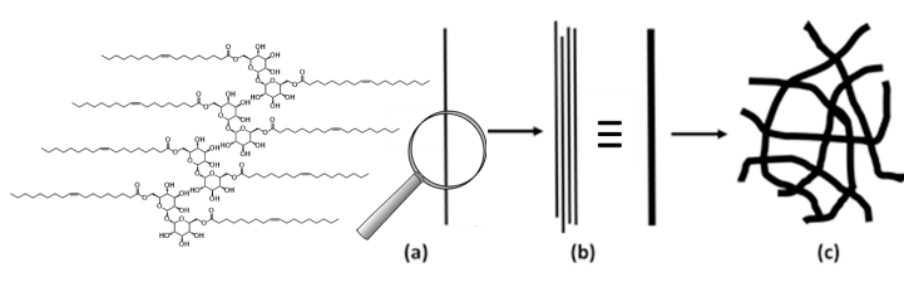

Figure 4: Proposed scheme of trehalose dioleate packing in the gel. (a) multilayer lamellar stacking to form fibers, (b) aggregates of fibers to form larger ones, (c) entanglement of the fibers to form the 3D-network.

\section{Rheological study}

The dynamic mechanical properties were evaluated by means of an oscillatory frequency sweep measurement between 0.02 and $10 \mathrm{~Hz}$ at a constant strain of $0.1 \%$ (see Figure 58). The frequency curves show a typical signature of gel with an elastic modulus almost constant with frequency and a viscous modulus ten times lower.

An oscillatory strain sweep measurement, performed between $0.01 \%$ and $100 \%$ at a constant frequency of $1 \mathrm{~Hz}$, shows that all the $G^{\prime}$ and $G^{\prime \prime}$ curves were typical of a gel. A first region (Figure 5, (a)) corresponds to a viscoelastic solid behaviour where $G^{\prime}$ is greatly predominant to $G^{\prime \prime}$ ( $G$ ' and $G^{\prime}$ " values do not change over this region). Above this region, a decrease of $G^{\prime}$ and a slight increase of $G^{\prime \prime}$ can be observed (Figure 5, (b)) and finally, values of $G$ " become higher than the ones of $G^{\prime}$ but the two curves sharply decrease (Figure 5, (c)) because of the destructuration of the gel. 


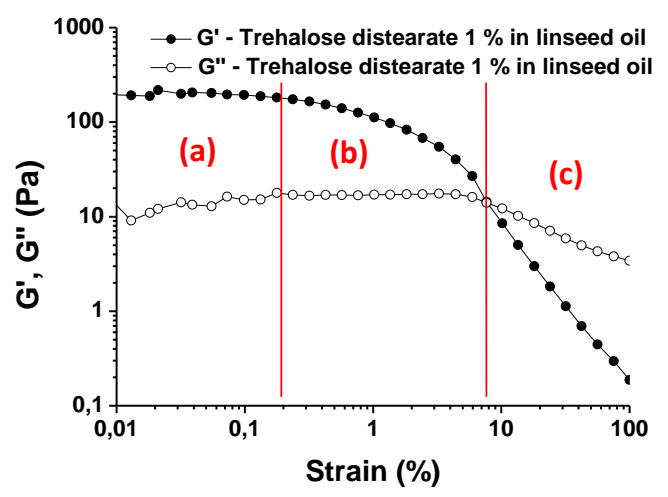

Figure 5: Oscillatory strain sweep measurement of the gel prepared with trehalose distearate in linseed oil at $1 \mathrm{wt} . \% / \mathrm{v}$. (a) Linear viscoelastic region, (b) break of entanglement points, (c) destruction of the gel.

It was easier to see the end of the linear viscoelastic domain by measuring the shear stress variation as a function of the strain (Figure 6).

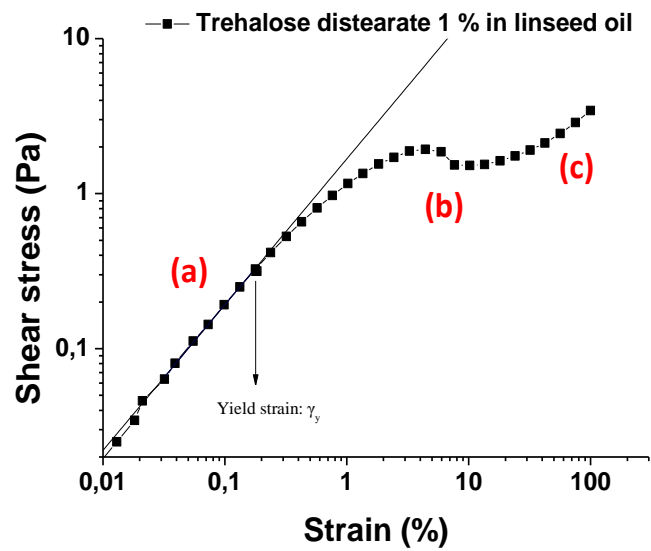

Figure 6: Shear stress curve of gel prepared with trehalose distearate at 1 $w t . \% / v$ in linseed oil obtained from oscillatory strain sweep.

The shear stress stays linear between $0.01 \%$ and $0.18 \%$ as illustrated in Figure 6, (region (a)). From this curve, the yield strain noted $\gamma_{y}$ can be evaluated as the strain corresponding to the end of the linear domain. Above $0.18 \%$ (Figure 6, (a)), a decrease of the shear stress is observed (Figure 6, (b)) and then the shear stress increases again (Figure 6, (c)). The decrease of the shear stress in a given shear range is not possible when a regular strain gradient is achieved in the sample and suggests a heterogeneity in the flow. It is interesting to mention that above a critical shear strain, these gels appear to become heterogeneous at the macroscopic scale, which can explain this non-homogeneous flow in the sample.

Gels with 3 different concentrations of gelator (1, 3 and 5 wt.\%) were made in the three selected vegetable oils (olive oil, linseed oil and castor oil) and the six gelators synthetized. Strain sweep and frequency sweep measurements were performed on these gels. These measurements reveal that $G^{\prime}$ and G" values increase and that $\sigma_{y}$ decreases as a function of the concentration (see Figure 59). All the $G^{\prime}, G^{\prime \prime}$ and $\sigma_{y}$ are reported in Table S1

\section{Effect of the lipidic chain on the rheological properties of the gel}

The effect of the structure of the fatty acid chain on the rheological properties of the gel was investigated. The effect of the cis-trans stereochemistry of the double bond present on trehalose diesters was first studied. Trehalose dielaidate and trehalose dioleate having one unsaturation with a trans or a cis configuration, respectively, showed similar behaviour under oscillatory strain sweep with a linear domain extended up to $\sim 1 \%$ (see Figure S10). However, gels formed with the trehalose dielaidate (trans configuration) showed higher $\mathrm{G}^{\prime}$ than the ones formed with the trehalose dioleate. The trans configuration brings more hardness to the gels, a feature that could be explained by the difference of the spatial chain arrangement. In the case of the trans configuration, the lipidic chain can be extended contrarily to the geometry imposed by the cis configuration, where the lipidic chain is bent, leading to smaller d-spacing (confirmed by XRS) and weaker fibril. Moreover, it could be also due to differences in fibers entanglement.

The effect of the number of unsaturations of the lipidic chain on the rheological properties of the gel was also investigated. The trehalose diesters with none, one or two double bonds with a cis configuration, i.e. the trehalose distearate, trehalose dioleate and trehalose dilinoleate, respectively were tested. For each vegetable oil, the gel from saturated trehalose diester exhibited higher $G^{\prime}$ and $G^{\prime \prime}$ with a lower $\gamma_{y}$ compared to the gels prepared with unsaturated diesters (See Figure S11). Harder gels were thus obtained with the saturated glycolipids. This feature confirmed the statement exposed before with the trans unsaturated trehalose dielaidate. In fact, one can anticipate that saturated glycolipid is totally extended in the vegetable oil contrarily to the unsaturated ones, which are bent due to the cis configuration of their double bonds. The trehalose diesters with two unsaturations on their lipidic moieties have higher $G^{\prime}$ values than the mono-unsaturated one. This is again in agreement with d-spacing which is higher with trehalose dilinoleate in comparison to the one of trehalose dioleate.

Finally, the effect of the lipidic chain length was investigated. Three trehalose diesters with different lipidic chain lengths were compared: trehalose diundecenoate (C11), trehalose dioleate (C18) and trehalose dierucate (C22). The shortest diester (Figure 7, black curve) shows higher $G^{\prime}$ and lower $\gamma_{y}$ than the two others. 


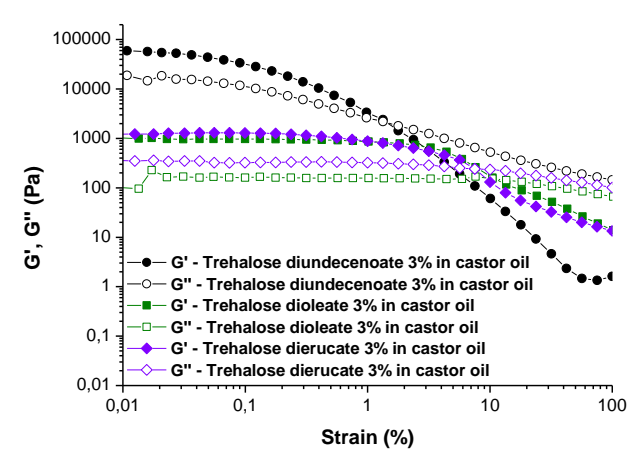

Figure 7: Effect of the lipidic chain length on the rheological properties of the gels Oscillatory strain sweep performed on gels made from trehalose diundecenoate (black curves), trehalose dioleate (green curves) and trehalose dierucate (purple curves) in castor oil at $3 \mathrm{wt} . \%$

Short lipidic chain favors the formation of gels with higher mechanical properties. In fact, the gels prepared with trehalose dioleate (C18) (Figure 7, green curve) and trehalose dierucate (C22) (Figure 7, purple curve) exhibit lower mechanical properties, with $\mathrm{G}^{\prime}$ and $\mathrm{G}^{\prime \prime}$ values 100 times lower than the ones of trehalose diundecenoate. This can be explained by the presence of the internal double bond with a cis configuration, which bends the lipidic chain.

\section{Conclusions}

In this study, trehalose diesters have been synthesized from a two-step procedure involving: i/ the transvinylation of fatty acids followed by ii/ a selective enzymatic transesterification of the primary alcohols of trehalose. The gelation properties of these trehalose diesters with various fatty acid chains were investigated in three vegetable oils (olive oil, linseed oil and castor oil). Microscopy analyses and X-ray scattering allowed us to determine the gel morphology. The so-formed gels are a tridimensional network composed of crystalline fibers, the latter constituted of stacked multi-layer lamellas of trehalose diesters. The rheological properties of the gels were also investigated, showing an influence of the lipidic chain nature. It was observed that short lipidic chain lengths favour the formation of harder gels (higher $G^{\prime}$ and $G^{\prime \prime}$ values) but also some brittleness (lower $\sigma_{y}$ ). Moreover, saturated diesters compared to unsaturated ones lead to the formation of harder gels as evidenced by higher $G^{\prime}$ and $G^{\prime \prime}$ values. In addition, the firmness of the gels increases with the concentration of the gelator due to an increase of the network density. However, the values of $G^{\prime}, G^{\prime \prime}$ and $\sigma_{y}$ are also very dependent on the vegetable oil. Therefore, it should be necessary to evaluate the rheological properties for each diester depending on the oil to reach the best properties according to a specific application.

\section{Acknowledgements}

The authors thank University of Bordeaux, Bordeaux INP, CNRS, Aquitaine Regional Council and ITERG for the financial support of this research. They also thank the Centre de Recherche Paul Pascal (CRPP) for X-ray analyses, Equipex
Xyloforest ANR-10-EQPX-16 XYLOFOREST for flash chromatography and Institut des Sciences Moléculaires (ISM) of the University of Bordeaux for SEM analyses.

\section{Notes and references}

1 N. E. Hughes, A. G. Marangoni, A. J. Wright, M. a. Rogers and J. W. E. Rush, Trends Food Sci. Technol., 2009, 20, 470-480.

2 F. Jimenez-Colmenero, L. Salcedo-Sandoval, R. Bou, S. Cofrades, A. M. Herrero and C. Ruiz-Capillas, Trends Food Sci. Technol., , DOI:10.1016/j.tifs.2015.04.011.

3 A. G. Marangoni, J. Am. Oil Chem. Soc., 2012, 89, 749-780.

4 K. Plamen, L. E. Cong, a N. H. Khanh, D. Alice, R. Halima, R. U. M. Silvia, V. Carla, H. Marek and P. Fabrice, Househ. Pers. Care Today, 2015, 10, 15-19.

5 S. Murdan, Expert Opin. Drug Deliv., 2005, 2, 489-505.

6 V. Faivre and V. Rosilio, Expert Opin. Drug Deliv., 2010, 7, 1031-1048.

7 M. A. Rogers, A. J. Wright and A. G. Marangoni, Soft Matter, 2009, 5, 1594.

8 M. Pernetti, K. F. van Malssen, E. Flöter and A. Bot, Curr. Opin. Colloid Interface Sci., 2007, 12, 221-231.

9 M. Djabourov, K. Nishinari and S. B. Ross-Murphy, Physical Gels from Biological and Synthetic Polymers, Cambridge University Press, 2013.

10 R. G. Weiss and P. Terech, Molecular gels: Materials with self-assembled fibrillar networks, Springer Netherlands, Dordrecht, 2006.

11 D. J. Abdallah and R. G. Weiss, Adv. Mater., 2000, 12, 1237-1247.

12 K. Hanabusa and M. Suzuki, Polym. J., 2014, 46, 776-782.

13 B. O. Okesola and D. K. Smith, Chem. Soc. Rev., 2016, 45, 4226-4251.

14 V. Ajay Mallia and R. G. Weiss, Soft Matter, 2016, 12, 3665-3676.

15 Y. Lan and M. a. Rogers, CrystEngComm, 2015, 17, 8031-8038.

16 P. T. Anastas and J. C. Warner, Green Chemistry: Theory and Practice, Oxford University Press, London, Oxford Uni., 1998.

17 G. Taylor, Energy Policy, 2008, 36, 4406-4409.

18 F. Cherubini, Energy Convers. Manag., 2010, 51, 1412-1421.

19 J. R. Silverman, M. Samateh and G. John, Eur. J. Lipid Sci. Technol., 2016, 118, 4755.

20 G. John, B. Vijai Shankar, S. R. Jadhav and P. K. Vemula, Langmuir, 2010, 26, 17843-17851.

21 P. K. Vemula and G. John, Acc. Chem. Res., 2008, 41, 769-782.

22 S. Datta and S. Bhattacharya, Chem. Soc. Rev., 2015, 44, 5596-5637.

23 G. Zhu and J. S. Dordick, Chem. Mater., 2006, 18, 5988-5995.

24 G. John, G. Zhu, J. Li and J. S. Dordick, Angew. Chemie, 2006, 45, 4772-4775.

25 S. R. Jadhav, P. K. Vemula, R. Kumar, S. R. Raghavan and G. John, Angew. Chem. Int. Ed. Engl., 2010, 49, 7695-8.

26 S. R. Jadhav, H. Hwang, Q. Huang and G. John, J. Agric. Food Chem., 2013, 61, 12005-12011.

27 M. W. Oosterom, F. Van Rantwijk and R. A. Sheldon, Biotechnol., 1996, 49, 328333.

28 L. Choplin, V. Sadtler, P. Marchal, D. Sfayhi, M. Ghoul and J. M. Engasser, J. Colloid Interface Sci., 2006, 294, 187-193

29 S; Prabhakar, T; Vivès, V. Ferrières, T. Benvegnu, L. Legentil and L. Lemiègre, Green Chem., 2017,19, 987-995

30 G. Hibert, E. Grau, D. Pintori, S. Lecommandoux and H. Cramail, Polym. Chem., 2017, 8, 3731-3739.

31 N. Garti, E. Wellner and S. Sarig, Krist. Techn., 1980, 15, 1303-1310.

32 M. Suzuki, K. Sato, N. Yoshimoto, S. Tanaka and M. Kobayashi, J. Am. Oil Chem. Soc., 1988, 65, 1942-1947

33 S. Ueno, T. Suetake, J. Yano, M. Suzuki and K. Sato, Chem. Phys. Lipids, 1994, 72, 27-34, 


\title{
Organogels from trehalose difatty esters amphiphiles
}

\author{
G. Hibert, ${ }^{a, b}$ M. Fauquignon, ${ }^{a, b}$ J.-F. Le Meins, ${ }^{a, b}$ D. Pintori, ${ }^{c}$ E. Grau, *a,b S. \\ Lecommandoux, ${ }^{* a, b}$ and H. Cramail*a,b \\ a.University of Bordeaux, Laboratoire de Chimie des Polymères Organiques, UMR 5629, \\ IPB/ENSCBP, 16 avenue Pey-Berland, F-33607 Pessac Cedex, France. \\ b. Centre National de la Recherche Scientifique, Laboratoire de Chimie des Polymères Organiques \\ UMR 5629 F-33607 Pessac Cedex, France. \\ c.ITERG, 11 rue Gaspard Monge, F-33600 Pessac, France.
}

\section{Experimental and Supporting Information}

\section{Experimental Methods}

\section{Synthesis}

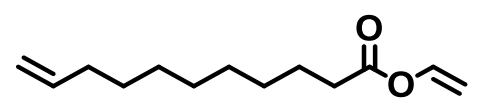

Vinyl undecenoate (1) (transvinylation of undecenoic acid): Undecenoic acid (1 eq) and a 15 eq. excess of vinyl acetate (VAc) was poured in a vial for the microwave reactor. Then, palladium acetate (0.05 eq.), and potassium hydroxide ( 0.10 eq.) were added and the resulting reaction mixture was stirred under microwave at $60{ }^{\circ} \mathrm{C}$ for $2 \mathrm{~h}$. The reaction mixture was diluted in DCM and then filtrated over celite to remove the palladium acetate, before removing the solvent with a rotary evaporator. The resulting residue was purified by silica gel flash chromatography using an elution gradient of $2-5 \% \mathrm{MeOH}$ in $\mathrm{DCM}$ to give the vinyl undecenoate. Yield: $95 \% .{ }^{1} \mathrm{H}$ NMR (DMSO- $\left.\mathrm{d}_{6}, 400 \mathrm{MHz}, \delta(\mathrm{ppm})\right): 7.29(\mathrm{~m}, 1 \mathrm{H},=\mathrm{C} \underline{\mathrm{H}}-\mathrm{OCO}-), 5.81\left(\mathrm{~m}, 1 \mathrm{H},-\underline{\mathrm{H}}=\mathrm{CH}_{2}\right), 4.97(\mathrm{~m}, 2 \mathrm{H}$, $\mathrm{C}_{2}=\mathrm{CH}-$ ), 4.88 (d, 1H, CH $\left.\mathrm{CH}_{2}=\underline{\mathrm{H}}-\mathrm{OCO}-\right)$, 4.56 (d, 1H, $\left.\mathrm{CH}_{2}=\mathrm{C} \underline{\mathrm{H}}-\mathrm{OCO}-\right), 2.37$ (t, 4H, - $\left.\underline{\mathrm{H}}_{2}-\mathrm{COO}-\right), 2.04$ (m, 4H, $\left.-\underline{\mathrm{CH}}_{2}-\mathrm{CH}=\mathrm{CH}-\right), 1.67\left(\mathrm{~m}, 4 \mathrm{H},-\underline{\mathrm{C}}_{2}-\mathrm{CH}_{2}-\mathrm{COO}-\right), 1.30\left(\mathrm{~m}, 2 \mathrm{H}\right.$, aliphatic $\left.-\underline{\mathrm{C}}_{2}-\right)$. 


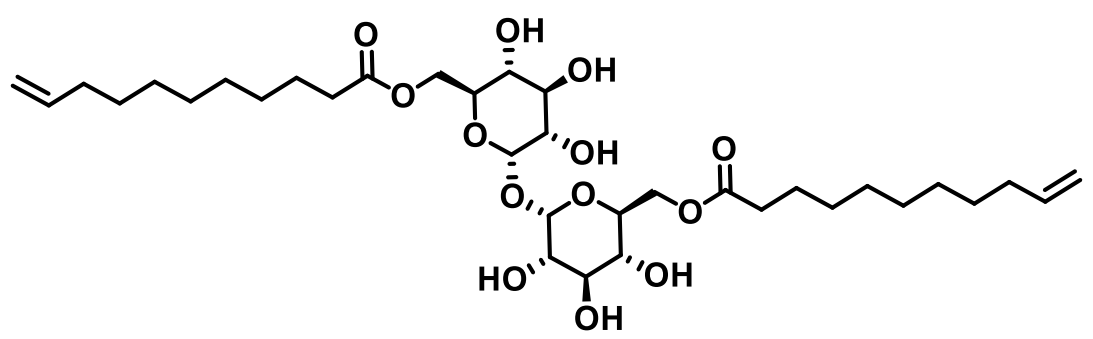

Trehalose diundecenoate (2) (enzymatic esterification of trehalose): The lipase (2.8 g) was added to a mixture of trehalose $(3 \mathrm{~g}, 9 \mathrm{mmol})$, vinyl ester $(6.8 \mathrm{~g}, 22 \mathrm{mmol}, 2.5 \mathrm{eq})$ in dry acetone $(40 \mathrm{~mL})$. The reaction mixture was stirred at $45{ }^{\circ} \mathrm{C}$ for $72 \mathrm{hr}$. After the reaction time, THF was added to well dissolve the diesters of trehalose, then the reaction mixture was filtered and the solvent was removed with the rotary evaporator. The obtained crude product was purified by silica gel flash chromatography using an elution gradient of $5-25 \%$ methanol in EtOAc-DCM (1:1) to give pure trehalose diesters as white solids. Yield: $50 \% .{ }^{1} \mathrm{H}$ NMR (DMSO-d $\mathrm{d}_{6}, 400 \mathrm{MHz}, \delta$ (ppm)): $5.78(\mathrm{~m}, 2 \mathrm{H},-\underline{\mathrm{C}}=\mathrm{CH} 2), 5.04$ (d, 2H, $-\mathrm{O} \underline{\mathrm{H}}, \mathrm{H} 4), 4.94(\mathrm{~m}, 4 \mathrm{H}, \mathrm{C} \underline{\mathrm{H}} 2=\mathrm{CH}-), 4.89$ (d, 2H, $-\mathrm{O} \underline{\mathrm{H}}$,

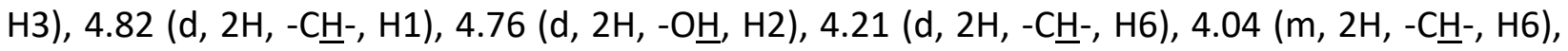
3.89 (m, 2H, $(\mathrm{t}, 4 \mathrm{H},-\mathrm{C} \underline{\mathrm{H}} 2-\mathrm{COO}-), 2.01(\mathrm{~m}, 4 \mathrm{H},-\mathrm{C} \underline{\mathrm{H}} 2-\mathrm{CH}=\mathrm{CH}-), 1.51(\mathrm{~m}, 4 \mathrm{H},-\mathrm{C} \underline{\mathrm{H}} 2-\mathrm{CH} 2-\mathrm{COO}-)$, 1.33-1.25 (m, $20 \mathrm{H}$, aliphatic $-\mathrm{C} \underline{\mathrm{H}} 2-)$ ).

The same two-step procedure was employed for the synthesis of the five following trehalose diesters

\section{Trehalose dioleate}

${ }^{1} \mathrm{H}$ NMR (DMSO-d6, 400MHz, $\delta(\mathrm{ppm})$ ): $5.31(\mathrm{~m}, 4 \mathrm{H},-\mathrm{C} \underline{\mathrm{H}}=\mathrm{CH}-), 5.04(\mathrm{~m}, 2 \mathrm{H},-\mathrm{OH}, \mathrm{H} 4), 4.87$ (d, 2H, $-\mathrm{OH}$, $\mathrm{H} 3), 4.83(\mathrm{~d}, 2 \mathrm{H},-\mathrm{C} \underline{\mathrm{H}}-, \mathrm{H} 1), 4.74(\mathrm{~d}, 2 \mathrm{H},-\mathrm{OH}, \mathrm{H} 2)$, , 4.24 (d, 2H, - $\left.\mathrm{C}_{-}-, \mathrm{H} 6\right), 4.03(\mathrm{~m}, 2 \mathrm{H},-\mathrm{CH}-, \mathrm{H} 6), 3.88$ (m,

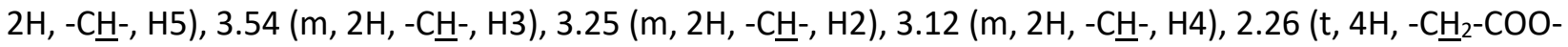
$\left.\mathrm{CH}_{3}\right), 1.98(\mathrm{~m}, 4 \mathrm{H},-\mathrm{CH}=\mathrm{C} \underline{\mathrm{H}} 2-), 1.50-1.24\left(\mathrm{~m}, 44 \mathrm{H}\right.$, aliphatic $\left.-\mathrm{CH}_{2}-\right), 0.85\left(\mathrm{t}, 6 \mathrm{H}\right.$, aliphatic $\left.-\mathrm{CH}_{3}\right) . \mathrm{Tm}=135^{\circ} \mathrm{C}$.

\section{Trehalose distearate}

${ }^{1} \mathrm{H}$ NMR (DMSO-d6, 400MHz, $\left.\delta(\mathrm{ppm})\right): 5.05(\mathrm{~m}, 2 \mathrm{H},-\mathrm{OH}, \mathrm{H} 4), 4.90(\mathrm{~d}, 2 \mathrm{H},-\mathrm{O} \underline{\mathrm{H}}, \mathrm{H} 3), 4.82$ (d, 2H, -Cㅡ-,

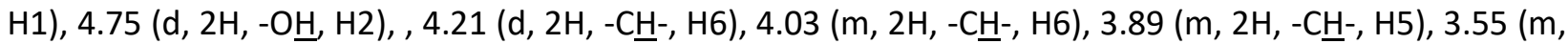
$2 \mathrm{H},-\mathrm{C} \underline{\mathrm{H}}-\mathrm{H} 3), 3.25(\mathrm{~m}, 2 \mathrm{H},-\mathrm{C} \underline{\mathrm{H}}-, \mathrm{H} 2), 3.12(\mathrm{~m}, 2 \mathrm{H},-\mathrm{C} \underline{\mathrm{H}}-\mathrm{H} 4), 2.26\left(\mathrm{t}, 4 \mathrm{H},-\mathrm{C}_{2}-\mathrm{COO}-\mathrm{CH}_{3}\right), 1.50-1.23(\mathrm{~m}$, $60 \mathrm{H}$, aliphatic $\left.-\mathrm{C}_{2}-\right), 0.85\left(\mathrm{t}, 6 \mathrm{H}\right.$, aliphatic $\left.-\mathrm{CH}_{3}\right)$.

\section{Trehalose diundecenoate}

${ }^{1} \mathrm{H}$ NMR (DMSO-d6, 400MHz, $\left.\delta(\mathrm{ppm})\right): 5.78\left(\mathrm{~m}, 2 \mathrm{H},-\mathrm{C} \underline{\mathrm{H}}=\mathrm{CH}_{2}\right), 5.05(\mathrm{~d}, 2 \mathrm{H},-\mathrm{OH}, \mathrm{H} 4), 4.97(\mathrm{~m}, 4 \mathrm{H}$, $\left.\mathrm{C}_{2}=\mathrm{CH}-\right), 4.87(\mathrm{~d}, 2 \mathrm{H},-\mathrm{OH}, \mathrm{H} 3), 4.82(\mathrm{~d}, 2 \mathrm{H},-\mathrm{C} \underline{\mathrm{H}}-, \mathrm{H} 1), 4.74(\mathrm{~d}, 2 \mathrm{H},-\mathrm{OH}, \mathrm{H} 2), 4.24(\mathrm{~d}, 2 \mathrm{H},-\mathrm{C} \underline{\mathrm{H}}-, \mathrm{H} 6), 4.02$

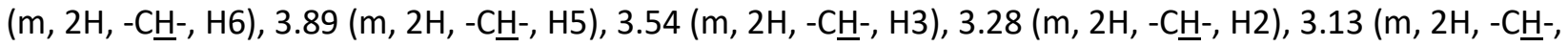
$\mathrm{H} 4), 2.27\left(\mathrm{t}, 4 \mathrm{H},-\underline{\mathrm{C}}_{2}-\mathrm{COO}-\right), 2.01\left(\mathrm{~m}, 4 \mathrm{H},-\underline{\mathrm{C}}_{2}-\mathrm{CH}=\mathrm{CH}-\right), 1.51-1.25\left(\mathrm{~m}, 28 \mathrm{H}\right.$, aliphatic $\left.-\mathrm{C}_{2}-\right)$.

\section{Trehalose dierucate}

${ }^{1} \mathrm{H}$ NMR (DMSO-d6, 400MHz, $\left.\delta(\mathrm{ppm})\right): 5.32(\mathrm{~m}, 4 \mathrm{H},-\mathrm{C} \underline{\mathrm{H}}=\mathrm{CH}-), 5.04(\mathrm{~m}, 2 \mathrm{H},-\mathrm{O} \underline{\mathrm{H}}, \mathrm{H} 4), 4.88(\mathrm{~d}, 2 \mathrm{H},-\mathrm{OH}$,

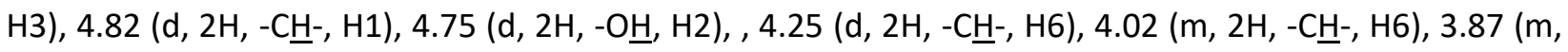




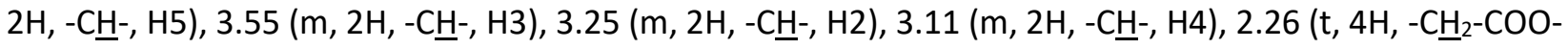
$\left.\mathrm{CH}_{3}\right), 1.98\left(\mathrm{~m}, 8 \mathrm{H},-\mathrm{CH}=\mathrm{C}_{2} 2^{-}\right), 1.50-1.24\left(\mathrm{~m}, 60 \mathrm{H}\right.$, aliphatic $\left.-\mathrm{CH}_{2}-\right), 0.85\left(\mathrm{t}, 6 \mathrm{H}\right.$, aliphatic $\left.-\mathrm{C}_{3}\right) . \mathrm{Tm}=151{ }^{\circ} \mathrm{C}$.

\section{Trehalose dilinoleate}

${ }^{1} \mathrm{H}$ NMR (DMSO-d6, 400MHz, $\delta(\mathrm{ppm})$ ): $5.32(\mathrm{~m}, 8 \mathrm{H},-\mathrm{C} \underline{\mathrm{H}}=\mathrm{CH}-), 5.03(\mathrm{~m}, 2 \mathrm{H},-\mathrm{O} \underline{\mathrm{H}}, \mathrm{H} 4), 4.87$ (d, 2H, $-\mathrm{OH}$,

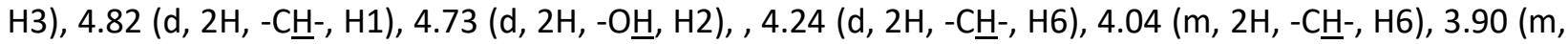
$\left.2 \mathrm{H},-\underline{\mathrm{C}}_{-}-\mathrm{H} 5\right), 3.55\left(\mathrm{~m}, 2 \mathrm{H},-\mathrm{C}_{-}-, \mathrm{H} 3\right), 3.26(\mathrm{~m}, 2 \mathrm{H},-\mathrm{C} \underline{\mathrm{H}}-, \mathrm{H} 2), 3.11(\mathrm{~m}, 2 \mathrm{H},-\mathrm{C} \underline{\mathrm{H}}-, \mathrm{H} 4), 2.73(\mathrm{t}, 4 \mathrm{H},-\mathrm{CH}=\mathrm{CH}-$ $\mathrm{C} \underline{\mathrm{H}} 2-\mathrm{CH}=\mathrm{CH}-), 2.26\left(\mathrm{t}, 4 \mathrm{H},-\mathrm{C}_{2}-\mathrm{COO}^{-} \mathrm{CH}_{3}\right), 2.02\left(\mathrm{~m}, 8 \mathrm{H},-\mathrm{CH}=\underline{\mathrm{C}}_{2}-\right), 1.50-1.25\left(\mathrm{~m}, 32 \mathrm{H}\right.$, aliphatic $\left.-\underline{\mathrm{C}}_{2}-\right)$, $0.86\left(\mathrm{t}, 6 \mathrm{H}\right.$, aliphatic $\left.-\underline{\mathrm{C}}_{3}\right) . \mathrm{Tm}=138^{\circ} \mathrm{C}$.

\section{Trehalose dielaidate}

${ }^{1} \mathrm{H}$ NMR (DMSO-d6, 400MHz, $\left.\delta(\mathrm{ppm})\right): 5.35(\mathrm{~m}, 4 \mathrm{H},-\mathrm{C} \underline{\mathrm{H}}=\mathrm{CH}-), 5.04(\mathrm{~m}, 2 \mathrm{H},-\mathrm{O} \underline{\mathrm{H}}, \mathrm{H} 4), 4.88(\mathrm{~d}, 2 \mathrm{H},-\mathrm{OH}$,

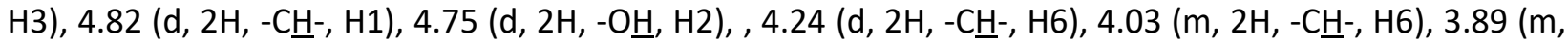

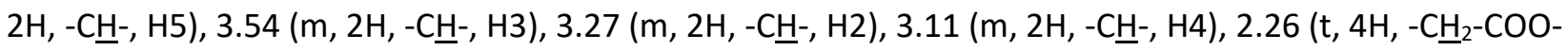
$\left.\mathrm{CH}_{3}\right), 1.93\left(\mathrm{~m}, 4 \mathrm{H},-\mathrm{CH}=\mathrm{CH}_{2}-\right), 1.50-1.24\left(\mathrm{~m}, 44 \mathrm{H}\right.$, aliphatic $\left.-\mathrm{CH}_{2}-\right), 0.85\left(\mathrm{t}, 6 \mathrm{H}\right.$, aliphatic $\left.-\mathrm{C}_{3}\right) . \mathrm{Tm}=148^{\circ} \mathrm{C}$.

\section{Gel preparation and gelation test}

Gel samples were prepared by adding a precise quantity of trehalose diesters to a desired solvent (vegetable oils and pharmaceutical grade oils), followed by heating and stirring until complete dissolution of the diesters in the vegetable oils. After getting a homogeneous solution, the mixture was cooled down to room temperature. The sample vials were inverted to confirm the gel formation.

To evaluate the efficiency of these trehalose diesters as gelators, the MGC of each diester was determined. The minimal gelation concentration (MGC) was determined by diluting the gel until getting a solution after the gelation procedure (homogenization by heating and shaking, and then cooling). 


\section{Supporting Information}
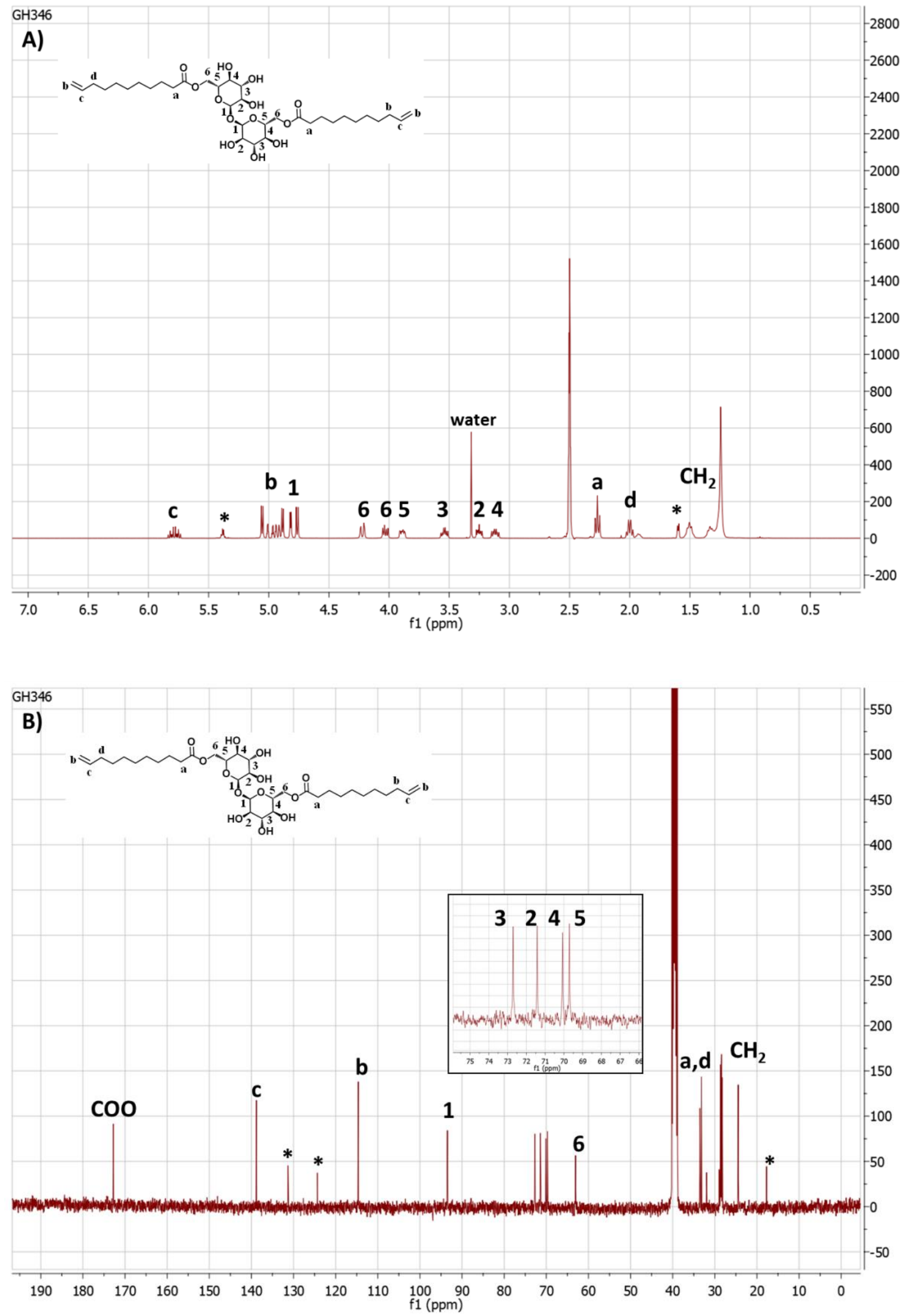

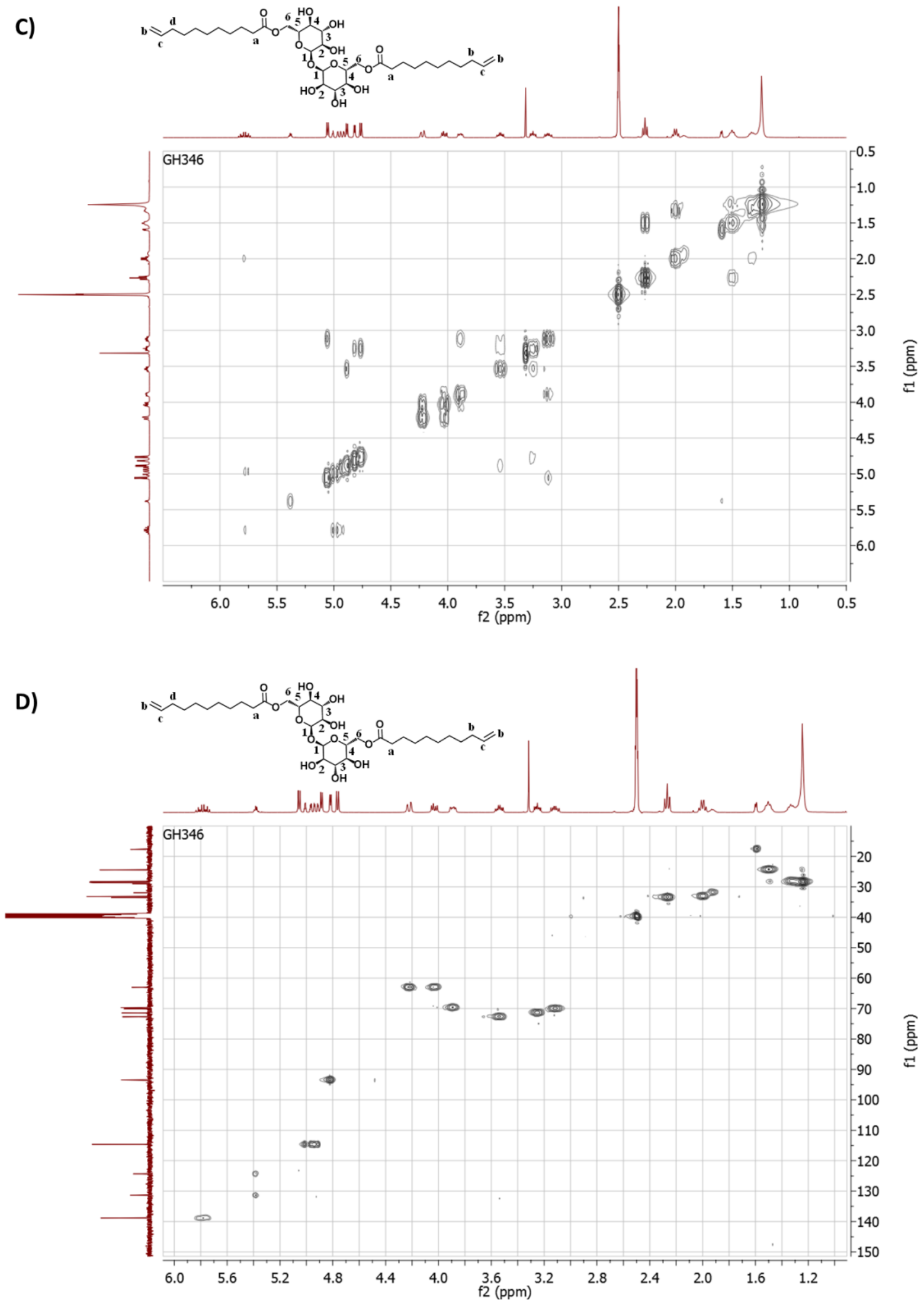


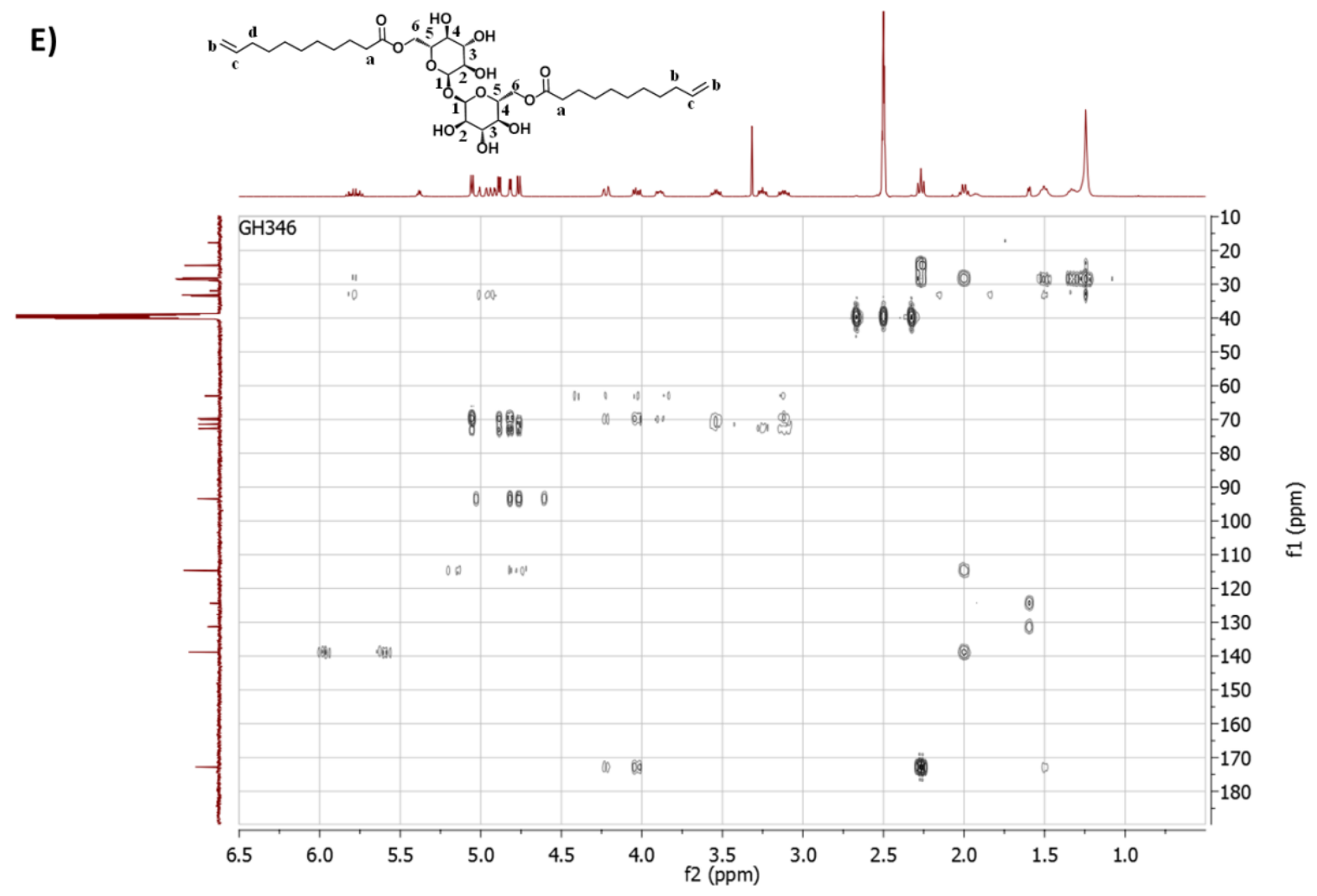

Figure S1: NMR spectra of trehalose diundecenoate performed in DMSO-d6. A) ${ }^{1} \mathrm{H}$ NMR, B) ${ }^{13} \mathrm{C} \mathrm{NMR,} \mathrm{C)}{ }^{1} \mathrm{H}-{ }^{1} \mathrm{H}$ COSY NMR, D) ${ }^{1} \mathrm{H}^{-13} \mathrm{C}$ HSQC NMR, E) ${ }^{1} \mathrm{H}^{13} \mathrm{C}$ HMBC NMR. *correspond to isomerized double bonds of trehalose diundecenoate

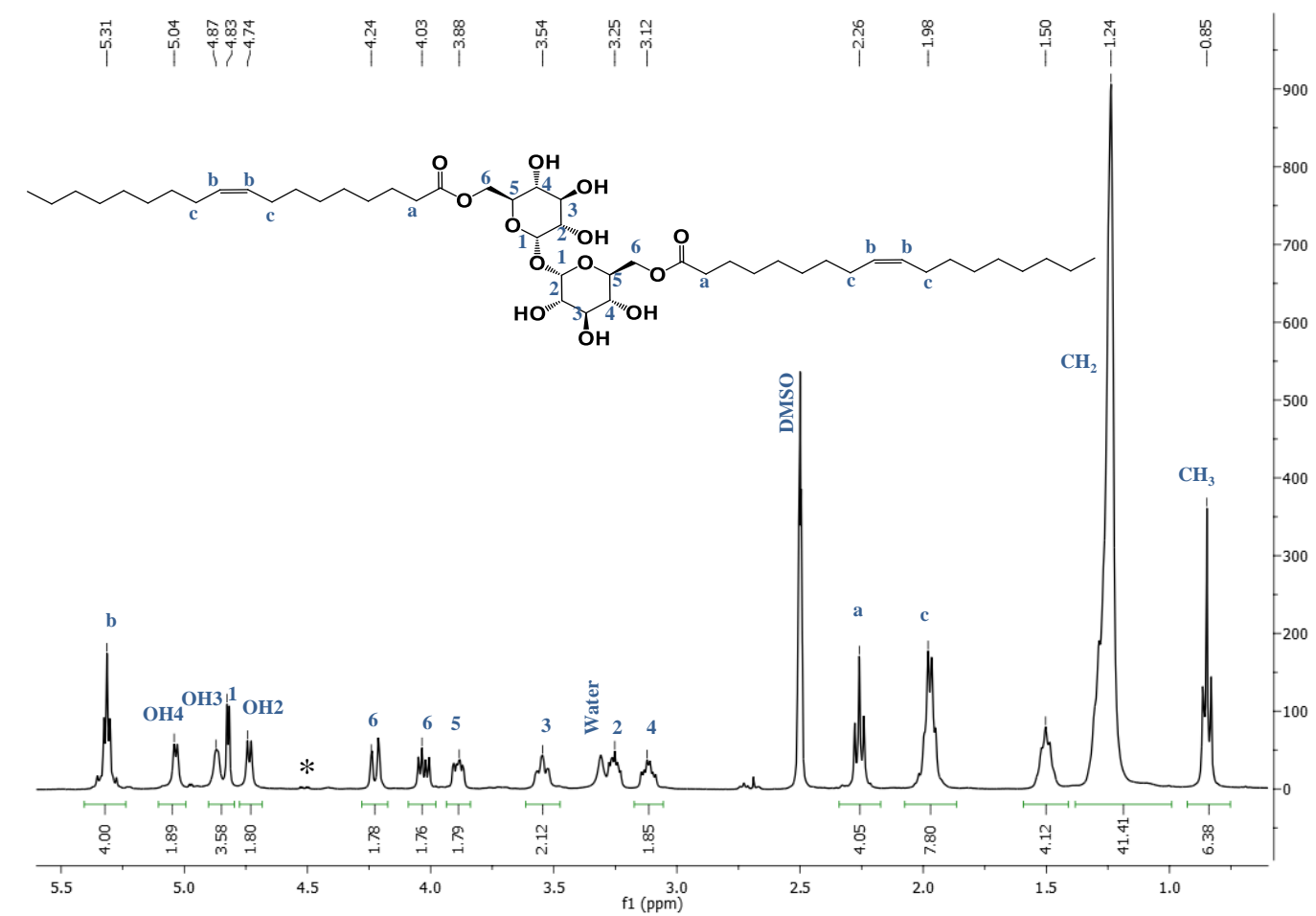

Figure S2: ${ }^{1} \mathrm{H}$ NMR spectrum of trehalose dioleate performed in DMSO-d6 *correspond to trehalose monooleate impurity 


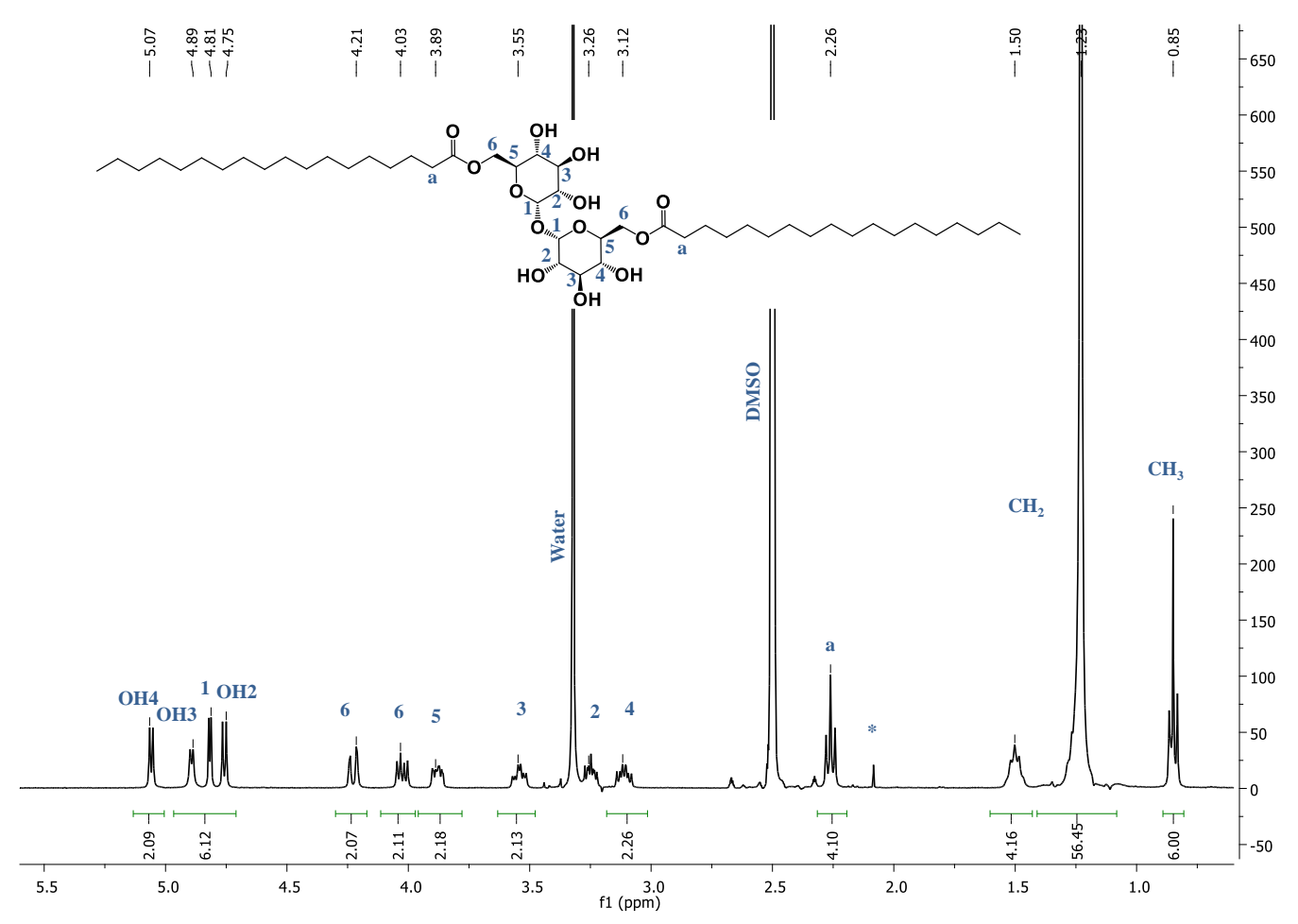

Figure S3: ${ }^{1} \mathrm{H}$ NMR spectrum of trehalose distearate performed in DMSO-d6

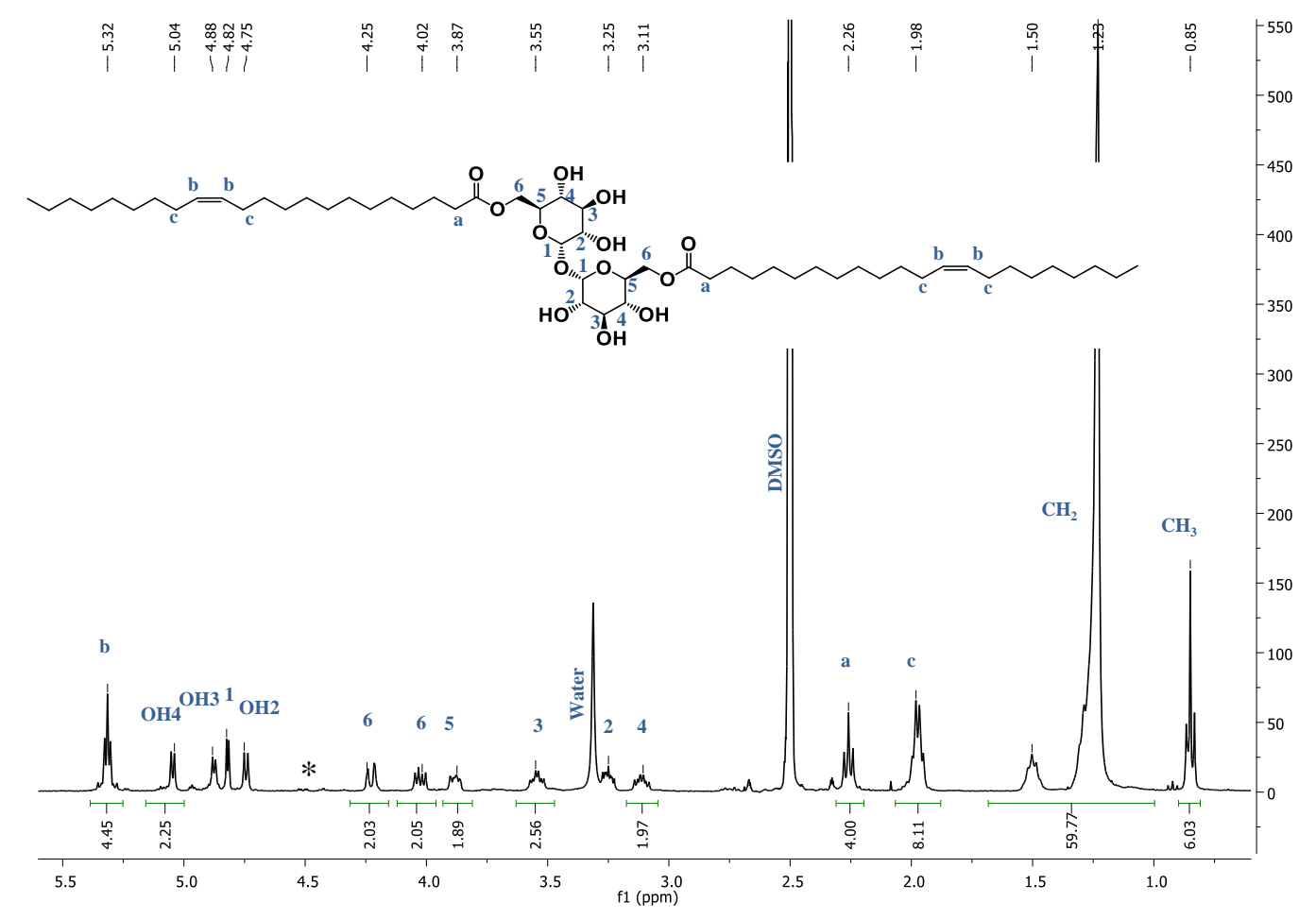

Figure S4: ${ }^{1} \mathrm{H}$ NMR spectrum of trehalose dierucate performed in DMSO-d6 *correspond to trehalose monoerucate impurity 


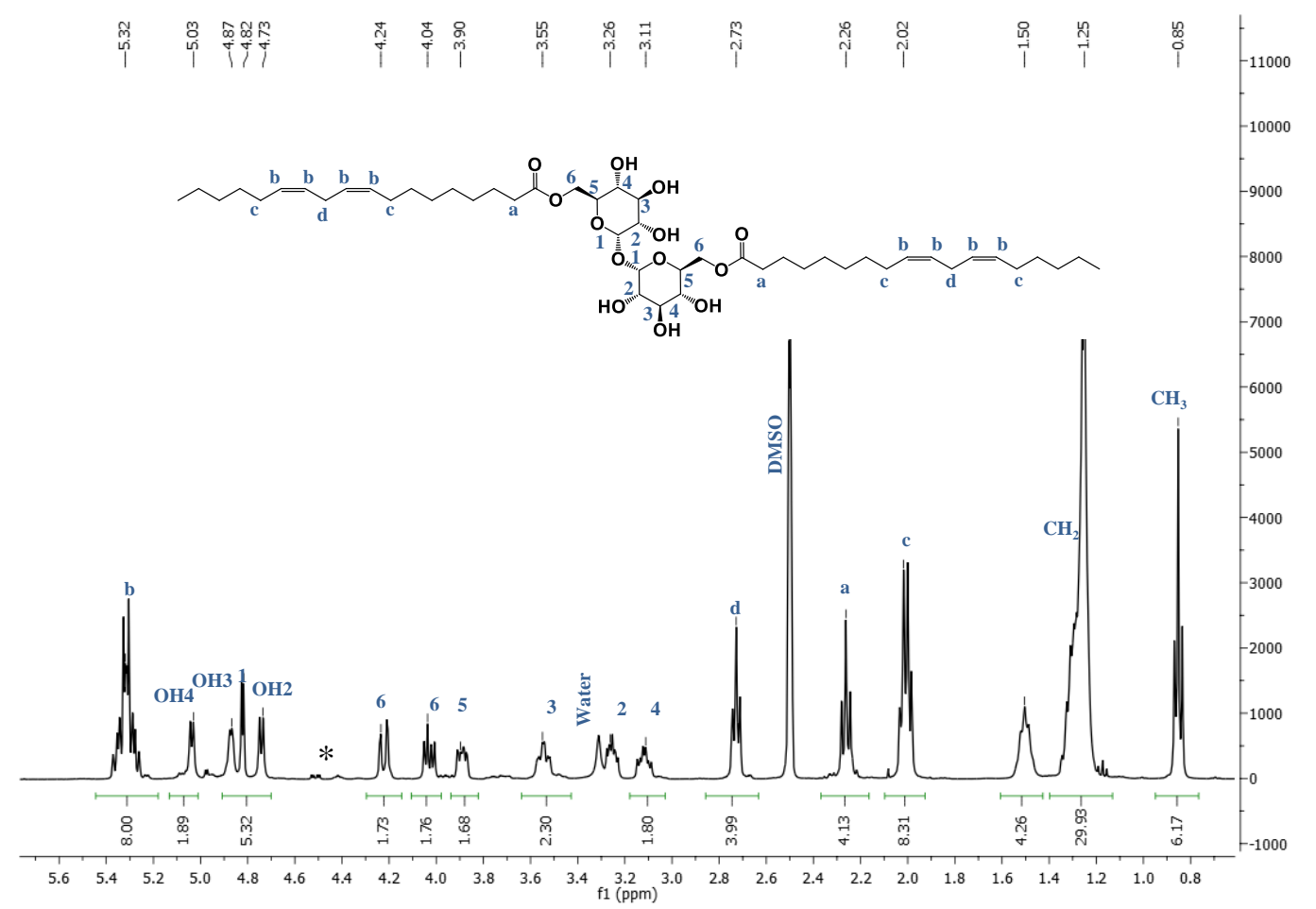

Figure S5: ${ }^{1} \mathrm{H}$ NMR spectrum of trehalose dilinoleate performed in DMSO-d6 *correspond to trehalose monolinoleate impurity

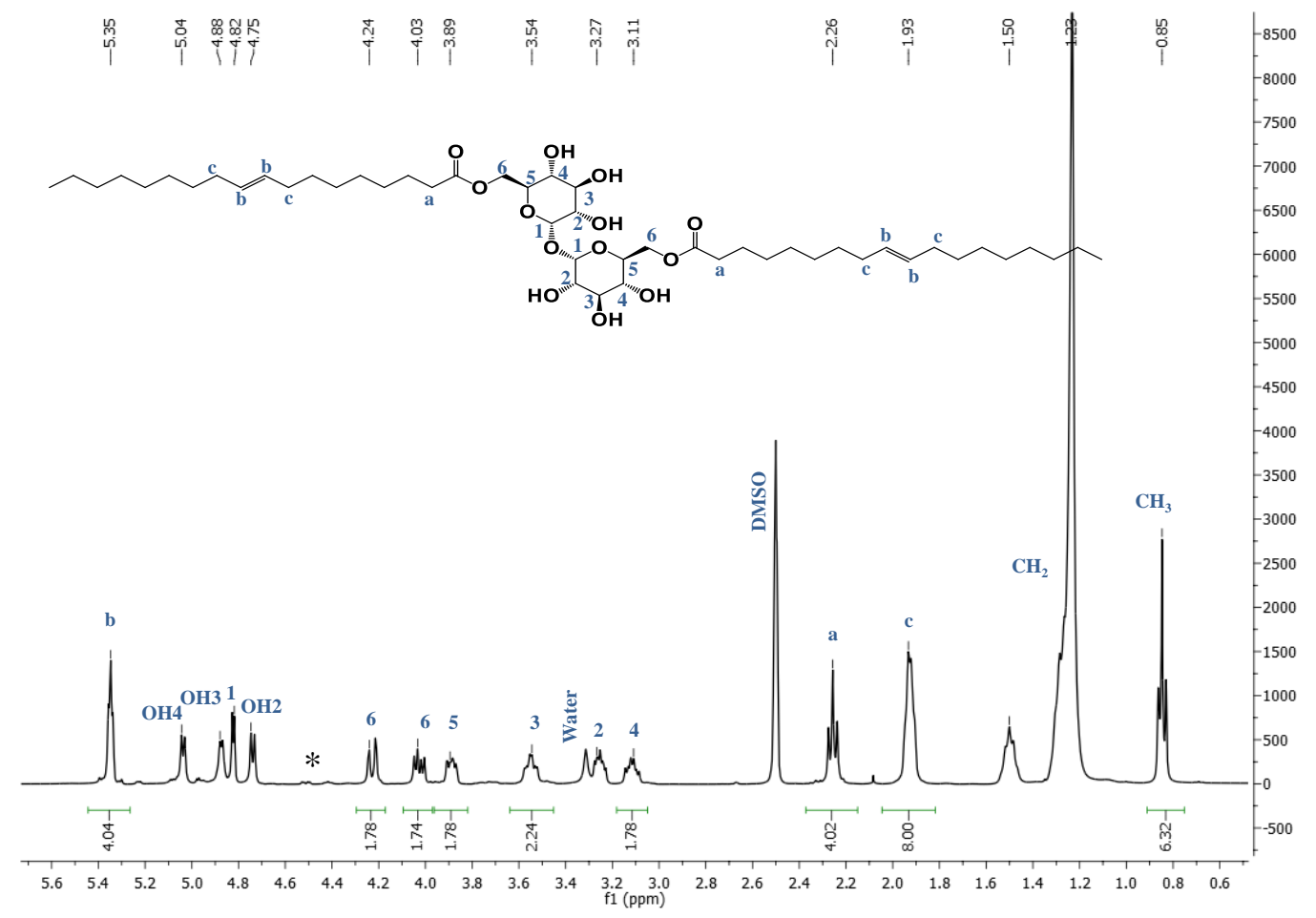

Figure S6: ${ }^{1} \mathrm{H}$ NMR spectrum of trehalose dielaidate performed in DMSO-d6 *correspond to trehalose monoelaidate impurity 

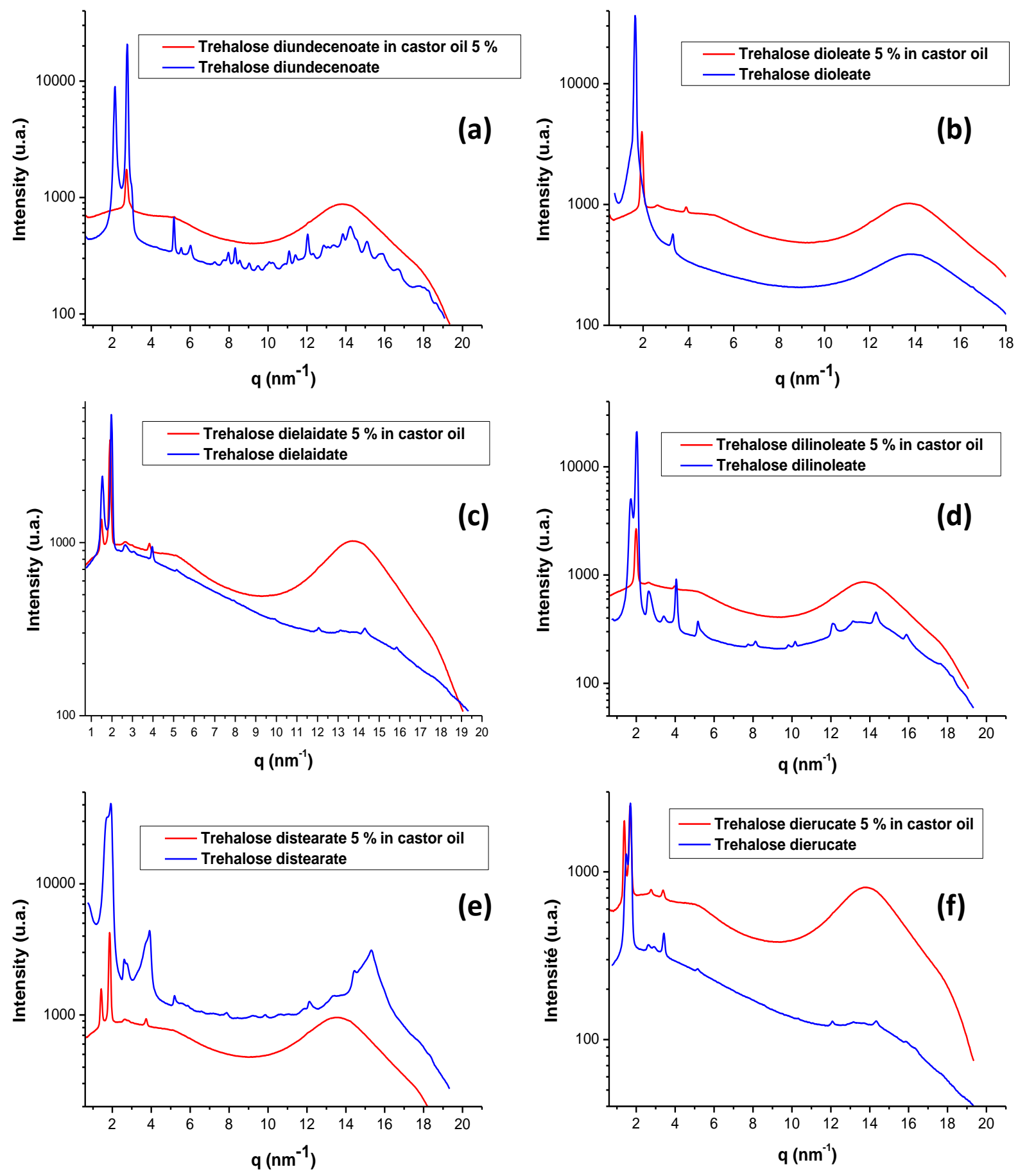

Figure S7: X-ray scattering patterns of pure trehalose diesters and of the gel in castor oil at 5 wt $\% / v$ 


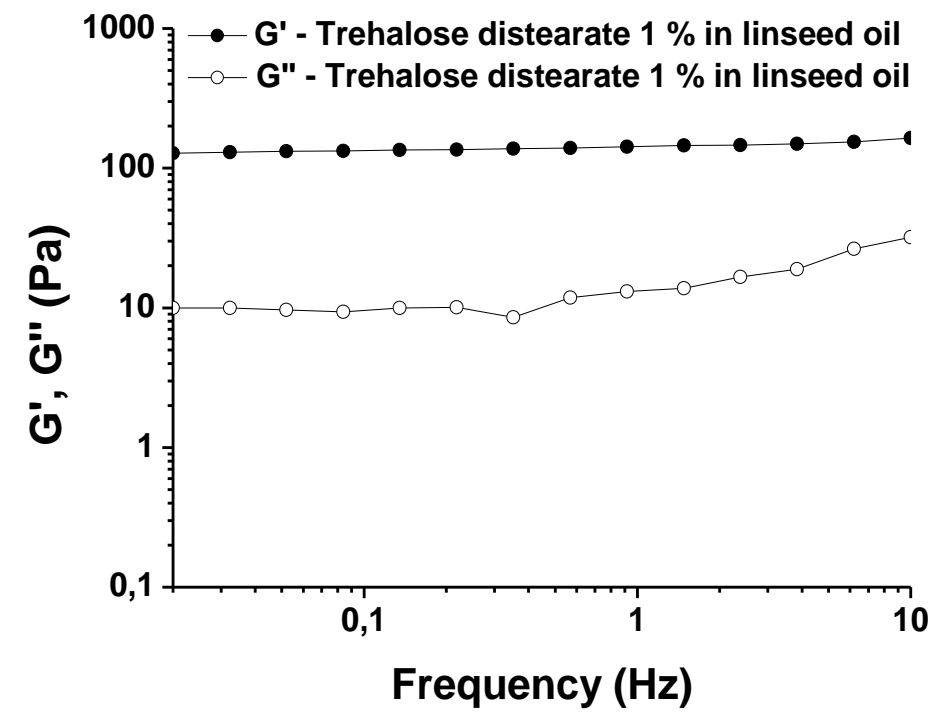

Figure S8: Oscillatory frequency sweep measurement of gel prepared with trehalose distearate in linseed oil at 1 wt.\%/v 

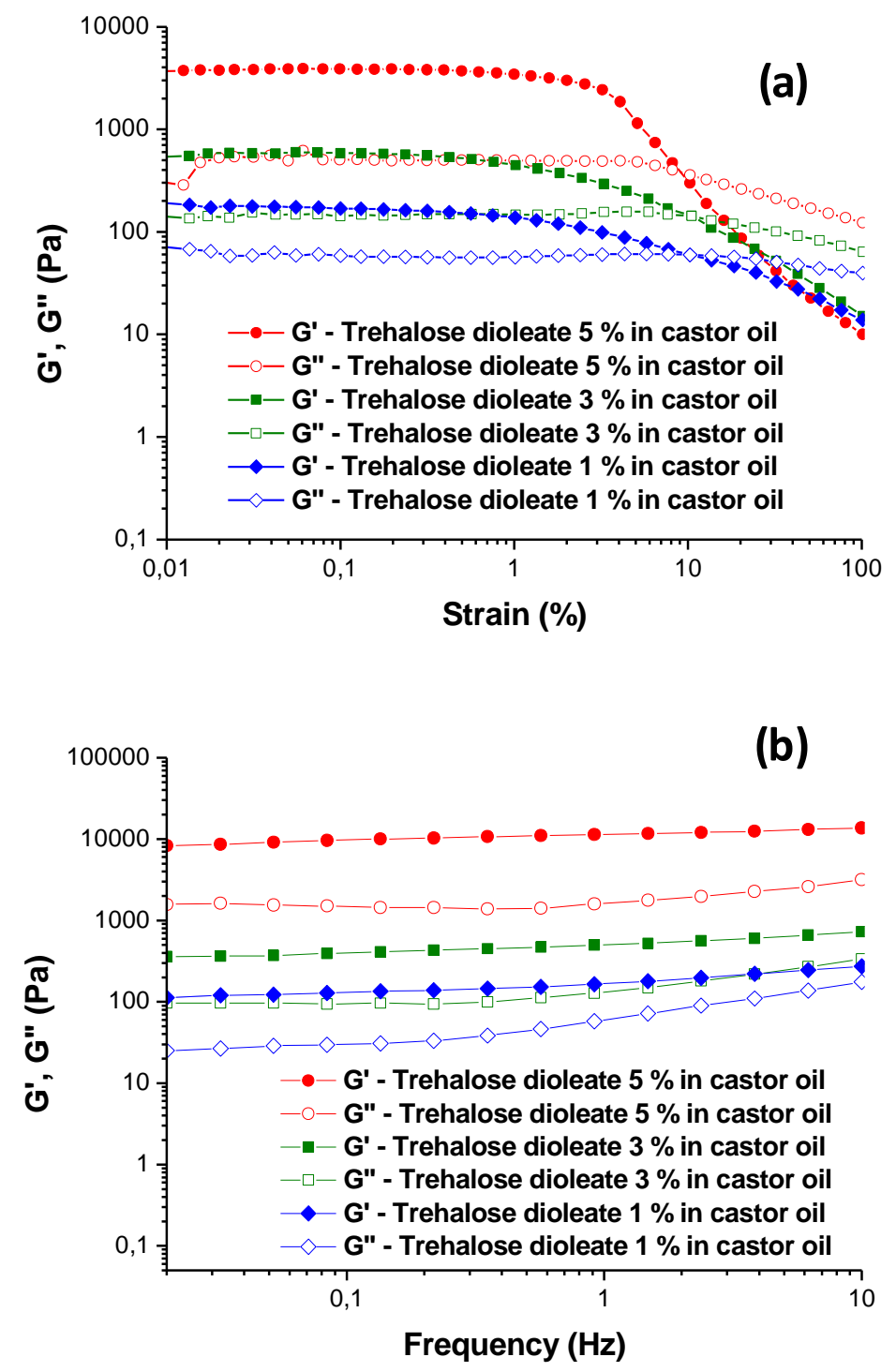

Figure S9: Concentration-dependent rheology measurement (strain sweep (a) and oscillatory frequency sweep (b)) of trehalose dioleate in castor oil 


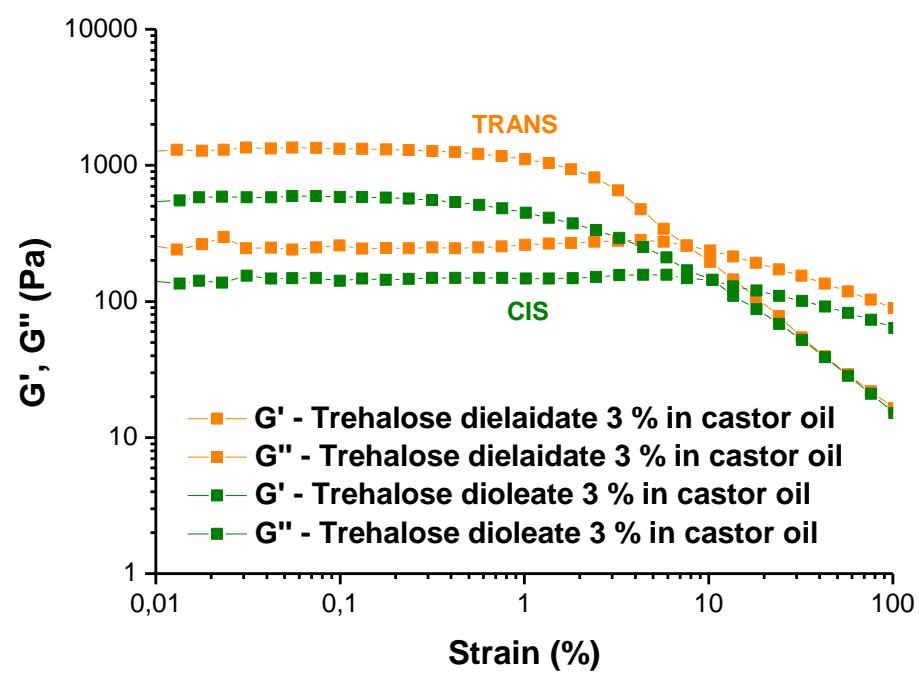

Figure S10: Effect of the cis-trans configuration on the rheological properties of gel in castor oil. Oscillatory strain sweep performed on gel made from trehalose dioleate (CIS) and trehalose dielaidate (TRANS) at 3 wt.\%/v

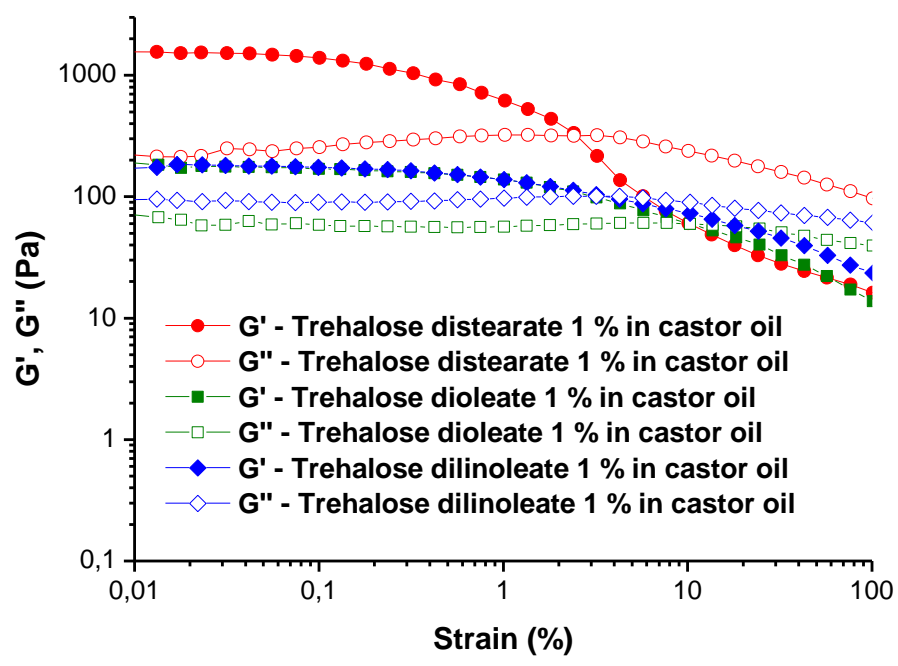

Figure S11: Effect of the unsaturation number of the alkyl chain on rheological properties of gel. Oscillatory strain sweep performed on gels made from trehalose distearate (red curve), trehalose dioleate (green curve) and trehalose dilinoleate (blue curve) in castor oil at 1 wt.\% 


\begin{tabular}{|c|c|c|c|c|c|c|}
\hline Glycolipids & Vegetable oil & wt. \% & Tgel-to-sol $\left({ }^{\circ} \mathrm{C}\right)$ & $\gamma_{\mathrm{y}}(\%)$ & $\mathbf{G}^{\prime}(\mathbf{P a})$ & $\mathrm{G}^{\prime \prime}(\mathrm{Pa})$ \\
\hline \multirow{8}{*}{$\begin{array}{c}\text { Trehalose Distearate } \\
\text { (C18:0) }\end{array}$} & \multirow{3}{*}{ Olive oil } & 1 & 133 & 0,6 & 300 & 20 \\
\hline & & 2 & 133 & 2,9 & 2600 & 300 \\
\hline & & 3 & 136 & 3,3 & 2800 & 360 \\
\hline & \multirow[t]{2}{*}{ Linseed oil } & 2 & 131 & 1,2 & 600 & 60 \\
\hline & & 3 & 134 & 1,6 & 2100 & 160 \\
\hline & \multirow{3}{*}{ Castor oil } & 1 & nd & 1,8 & 1500 & 200 \\
\hline & & 2 & nd & 33,5 & 12700 & 240 \\
\hline & & 3 & 124 & 12,5 & 16000 & 1700 \\
\hline \multirow{9}{*}{$\begin{array}{c}\text { Trehalose Dioleate } \\
\text { (C18:1) }\end{array}$} & \multirow{3}{*}{ Olive oil } & 1 & 119 & 0,3 & 20 & 10 \\
\hline & & 2 & 132 & 1,5 & 500 & 70 \\
\hline & & 3 & 124 & 1,8 & 600 & 90 \\
\hline & \multirow{3}{*}{ Linseed oil } & 1 & 122 & 0,5 & 30 & 10 \\
\hline & & 2 & 126 & 0,7 & 500 & 40 \\
\hline & & 3 & 125 & 0,9 & 700 & 100 \\
\hline & \multirow{3}{*}{ Castor oil } & 1 & nd & 1,6 & 200 & 50 \\
\hline & & 2 & 114 & 1,8 & 600 & 70 \\
\hline & & 3 & 111 & 20,2 & 4200 & 500 \\
\hline \multirow{9}{*}{$\begin{array}{l}\text { Trehalose Dilinoleate } \\
\text { (C18:2) }\end{array}$} & \multirow{3}{*}{ Olive oil } & 1 & nd & 0,2 & 60 & 20 \\
\hline & & 2 & 112 & 4,8 & 2500 & 400 \\
\hline & & 3 & 120 & 5 & 1900 & 200 \\
\hline & \multirow{3}{*}{ Linseed oil } & 1 & 121 & 0,5 & 50 & 20 \\
\hline & & 2 & 115 & 2,3 & 2300 & 300 \\
\hline & & 3 & 123 & & & \\
\hline & \multirow{3}{*}{ Castor oil } & 1 & 97 & 1 & 300 & 100 \\
\hline & & 2 & 104 & 1,7 & 600 & 200 \\
\hline & & 3 & 104 & 5,1 & 2400 & 400 \\
\hline \multirow{3}{*}{$\begin{array}{l}\text { Trehalose Dielaidate } \\
\text { (C18:1 trans) }\end{array}$} & \multirow{3}{*}{ Olive oil } & 1 & nd & 0,3 & 60 & 15 \\
\hline & & 2 & 126 & 1,5 & 400 & 60 \\
\hline & & 3 & 124 & 3,1 & 1100 & 100 \\
\hline
\end{tabular}




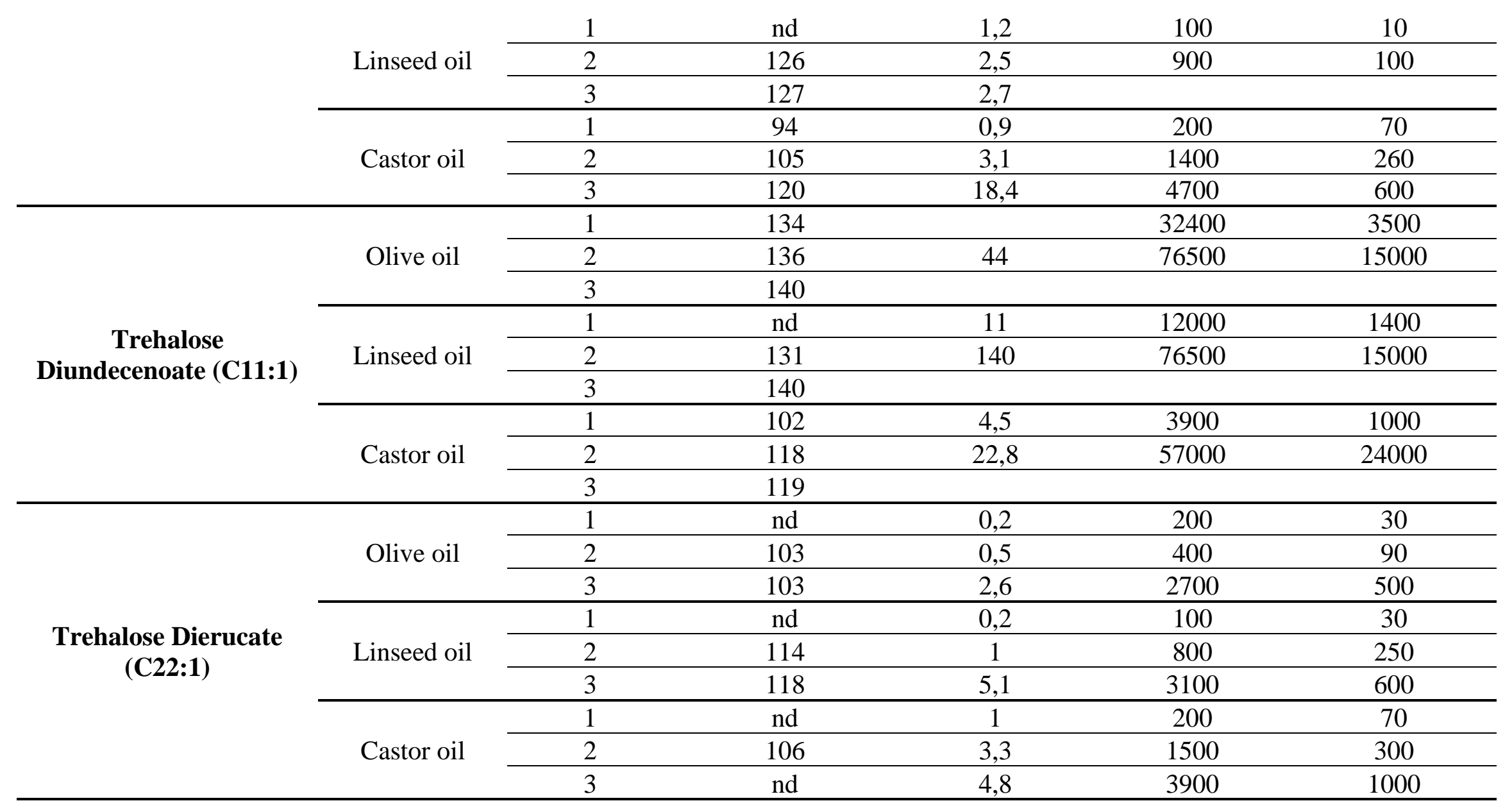

Table S1: Gel-to-sol temperature and rheological data of the gels. 